\title{
Ab Initio Thermochemistry of the Hydrogenation of Hydrocarbon Radicals Using Silicon-, Germanium-, Tin-, and Lead-Substituted Methane and Isobutane
}

\author{
Berhane Temelso ${ }^{\dagger}$ C. David Sherrill, ${ }^{*}, \dagger$ Ralph C. Merkle, ${ }^{*}, *$ and Robert A. Freitas, Jr.*, \\ Center for Computational Molecular Science and Technology, School of Chemistry and Biochemistry, \\ Georgia Institute of Technology, Atlanta, Georgia 30332-0400, College of Computing, Georgia Institute of \\ Technology, Atlanta, Georgia 30332-0280, and Institute for Molecular Manufacturing, 555 Bryant Street, \\ Suite 354, Palo Alto, California 94301
}

Received: March 5, 2007; In Final Form: June 21, 2007

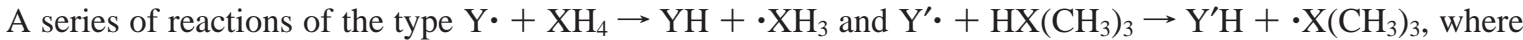
$\mathrm{Y}=\mathrm{H}, \mathrm{CH}_{3} ; \mathrm{Y}^{\prime}=\mathrm{CH}_{3}, \mathrm{C}\left(\mathrm{CH}_{3}\right)_{3} ;$ and $\mathrm{X}=\mathrm{Si}, \mathrm{Ge}, \mathrm{Sn}, \mathrm{Pb}$ are studied using state-of-the-art ab initio electronic structure methods. Second-order Møller-Plesset perturbation theory; the coupled-cluster singles, doubles, and perturbative triples method; and density functional theory are used with correlation-consistent basis sets (cc-pVNZ, where $\mathrm{N}=\mathrm{D}, \mathrm{T}, \mathrm{Q}$ ) and their pseudopotential analogs (cc-pVNZ-PP) to determine the transitionstate geometries, activation barriers, and thermodynamic properties of these reactions. Trends in the barrier heights as a function of the group IVA atom ( $\mathrm{Si}, \mathrm{Ge}, \mathrm{Sn}$, and $\mathrm{Pb})$ are examined. With respect to kinetics and thermodynamics, the use of a hydrogen attached to a group IVA element as a possible hydrogen donation tool in the mechanosynthesis of diamondoids appears feasible.
\end{abstract}

\section{Introduction}

Abstracting surface hydrogens to create radical sites, or rehydrogenation of radical sites, can help control the reactivity of surfaces. One proposed scheme that attempts to take advantage of the abstraction and rehydrogenation process to control reactivity is the mechanosynthesis of diamondoids. ${ }^{1-10}$ Mechanosynthesis is a paradigm that proposes to attach a molecular tooltip to a scanning probe microscope (SPM) to perform elementary synthetic operations, such as carbon deposition or hydrogen abstraction/donation, at a specific location on the substrate. The first elementary step, namely, hydrogen abstraction, is critical in mechanosynthesis and is an important part of many chemical processes, such as chemical vapor deposition (CVD) of diamond. In the CVD synthesis of diamond, a precursor hydrocarbon gas such as methane enters a plasma, thermal, or electric activation chamber in excess hydrogen gas. The activation process leads to the formation of atomic hydrogen, which abstracts hydrogen from the gas-phase hydrocarbons to yield very reactive carbon-containing radicals. These radicals deposit on the substrate and form carbon-carbon bonds, leading to diamond growth. Atomic hydrogens also abstract hydrogen from the diamond surface, thereby creating nucleation sites for further diamond growth. Regarding the mechanosynthesis of diamondoids, hydrogen abstraction has been carefully studied in several works. ${ }^{1,11-14}$ In a recent highlevel ab initio theoretical study, we found that hydrogen abstraction from saturated hydrocarbons using ethynyl radical is highly exothermic and has a very small barrier. ${ }^{15}$ In the case of ethynyl radical abstracting a hydrogen from isobutane, which has been suggested as a good model for diamond C(111) surface,$^{16}$ the reaction is virtually barrierless, indicating that an

* To whom correspondence should be addressed. E-mail addresses: sherrill@gatech.edu; merkle@cc.gatech.edu; rfreitas@rfreitas.com.

${ }^{\dagger}$ School of Chemistry and Biochemistry, Georgia Institute of Technology.

College of Computing, Georgia Institute of Technology.

$\S$ Institute for Molecular Manufacturing.
SPM tip with an ethynyl radical moiety could serve as a viable hydrogen abstraction tool. Such an approach has already been demonstrated theoretically and experimentally with non-ethynyl tips for the abstraction of hydrogens from a $\mathrm{Si}(100)$ surface and the selective manipulation of silicon atoms. ${ }^{17}$

Naturally, the next elementary step would be hydrogen donation to radical sites, and a few promising works have appeared in recent years. Yamamoto et al. ${ }^{18}$ demonstrated the deposition of hydrogen atoms from a scanning tunneling microscope (STM) with a tungsten tip to a monohydride Si(100)- $2 \times 1: \mathrm{H}$ surface through the application of a $+3.5 \mathrm{~V}$ voltage bias to diffuse the hydrogens to the tungsten tip, followed by $-8.5 \mathrm{~V}, 300 \mathrm{~ms}$ pulses to induce electronic excitations that break the tungsten-hydrogen bond. Thirstrup et al. ${ }^{19}$ used clean and hydrogen-covered STM tips to perform atomic-scale desorption and deposition of hydrogens from $\mathrm{Si}$ $(001)-(2 \times 1)-\mathrm{H}$ and $\mathrm{Si}(001)-(3 \times 1)-\mathrm{H}$ surfaces for both positive and negative sample bias voltages with a resolution of one to two atomic rows. McIntyre et al., ${ }^{20}$ in an effort to demonstrate nanocatalytic capabilities of a platinum-rhodium STM tip operating in a reactor cell with excess $\mathrm{H}_{2}$, managed to rehydrogenate partially dehydgrogenated carbonaceous fragments on a $\mathrm{Pt}(111)$ surface. In another study of catalytic hydrogenation, Müller et al. ${ }^{21}$ used a platinum-coated atomic force microscope tip to hydrogenate terminal azide groups on a self-assembled monolayer. They suggested that variation of the catalytic tip and surface could enable the fabrication of structures that cannot be made by conventional techniques. Shimokawa et al. ${ }^{22}$ studied the temperature dependence of thermal desorption, abstraction, and collision-induced desorption of $\mathrm{H}_{2}$ and $\mathrm{D}_{2}$ from $\mathrm{Ge}(100)$ and $\mathrm{Si}(100)$ surfaces.

In contrast to these experimental studies, there has been little theoretical work proposing candidate tools for the rehydrogenation of reactive surfaces as it pertains to mechanosynthesis. ${ }^{3,5}$ The simplest rehydrogenation reaction would involve the transfer of a weakly bound hydrogen to a hydrocarbon radical site. A 
hydrogen atom bonded to a group IVA $(\mathrm{Si}, \mathrm{Ge}, \mathrm{Sn}$, or $\mathrm{Pb})$ element in a substituted hydrocarbon is one possibility for a hydrogen donor to a carbon radical. A few theoretical and experimental works have explored a set of relevant reactions. Song et al. ${ }^{23}$ used the breathing orbital valence bond ${ }^{24}$ and a variety of other models built upon valence bond (VB) theory to compute barriers to nonsymmetric (nonidentity) reactions of type $\mathrm{X}+\mathrm{X}^{\prime} \mathrm{H} \rightarrow \mathrm{XH}+\mathrm{X}^{\prime}$ where $\mathrm{X} \neq \mathrm{X}^{\prime}=\mathrm{H}, \mathrm{CH}_{3}, \mathrm{SiH}_{3}$, $\mathrm{GeH}_{3}, \mathrm{SnH}_{3}$, and $\mathrm{PbH}_{3}$. Their VB estimates for barriers and reaction energies deviated by as much as $7 \mathrm{kcal} \mathrm{mol}^{-1}$ from those computed using MP2. Drozdova et al. ${ }^{25}$ studied hydrogen abstraction from $\mathrm{Ge}$ - and Sn-containing species by radicals. Chatgilialoglu et al. ${ }^{26}$ investigated the reaction of germanium hydrides to determine their hydrogen donation abilities. Zavitsas et al. $^{27}$ devised a scheme to predict activation energies of hydrogen abstraction reactions by radicals on the basis of bond dissociation energy, bond length, and infrared stretching frequency of the reactants and products. They then applied their model to 47 reactions, including some relevant to this work, and achieved fairly good agreement with experiment. Despite these and other studies on the adsorption and desorption of hydrogen from surfaces of group IVA atoms, ${ }^{28-30}$ there remains a lack of high-level ab initio or experimental data on the hydrogen exchange reactions for simple hydrocarbons, such as methane and isobutane with their group IVA-substituted counterparts.

High-level quantum chemical methods are capable of providing very accurate estimates of reaction thermodynamics. Indeed, the so-called Gaussian-1, ${ }^{31}$ Gaussian-2, ${ }^{32,33}$ and Gaussian-3, ${ }^{34-36}$ composite methods and their variants can provide reaction enthalpies typically within $1-2 \mathrm{kcal} \mathrm{mol}^{-1}$ of experiment. Although these theoretical approaches are rather expensive computationally and applicable only to small molecular systems, they demonstrate that truly high-quality energetics are possible using modern ab initio methods. In a continued effort to explore the feasibility of mechanosynthesis of diamondoids, an understanding of the thermochemistry and kinetics involved in the elementary processes becomes imperative, and modern theoretical methods are very useful in this endeavor. This work applies high level ab initio methods, including coupled-cluster theory, to predict reaction thermodynamics for a set of hydrogen donation reactions and proposes a prototype hydrogen donation tool.

\section{Theoretical Methodology}

The hydrogen transfer reactions considered in this study are given in reactions $1-4$ along with the point-group symmetry considered for the reaction (and the corresponding Abelian computational subgroup); $\mathrm{X}=\mathrm{Si}, \mathrm{Ge}, \mathrm{Sn}, \mathrm{Pb}$.

$$
\begin{aligned}
& \mathrm{H} \cdot+\mathrm{XH}_{4} \rightarrow \mathrm{H}_{2}+\cdot \mathrm{XH}_{3} \quad C_{3 v} / C_{s} \\
& \cdot \mathrm{CH}_{3}+\mathrm{XH}_{4} \rightarrow \mathrm{CH}_{4}+\cdot \mathrm{XH}_{3} \quad C_{3 v} / C_{s} \\
& \cdot \mathrm{CH}_{3}+\mathrm{HX}\left(\mathrm{CH}_{3}\right)_{3} \rightarrow \mathrm{CH}_{4}+\cdot \mathrm{X}_{\left(\mathrm{CH}_{3}\right)_{3} \quad C_{3 v} / C_{s}} \\
& \cdot \mathrm{C}\left(\mathrm{CH}_{3}\right)_{3}+\mathrm{HX}\left(\mathrm{CH}_{3}\right)_{3} \rightarrow \mathrm{HC}\left(\mathrm{CH}_{3}\right)_{3}+\cdot \mathrm{X}_{\left(\mathrm{CH}_{3}\right)_{3}} \\
& C_{3 v} / C_{s}
\end{aligned}
$$

Dunning's correlation consistent basis sets (cc-pVNZ, $\mathrm{N}=$ $\mathrm{D}, \mathrm{T}, \mathrm{Q}),{ }^{37,38}$ which provide a systematic convergence of energies and properties toward the complete basis set limit were used where available. For reactions involving the heavier atoms germanium, tin, and lead, we use Peterson's ${ }^{39,40}$ small-core
TABLE 1: Quality of Small- and Large-Core

Pseudopotentials: Classical Activation Barriers $\left(\Delta E^{\ddagger}\right)$ and Reaction Energies $\left(\Delta E\right.$, $\left.\mathrm{kcal} \mathrm{mol}^{-1}\right)$ for $\mathbf{H} \cdot+\mathbf{G e H}_{4} \rightarrow \mathbf{H}_{2}+$ $\cdot \mathrm{GeH}_{3}$

\begin{tabular}{lcrrrr}
\hline & size $\left(\mathrm{e}^{-} \mathrm{s}\right.$ in core $)$ & B3LYP & BHLYP & MP2 & CCSD(T) \\
\hline & \multicolumn{5}{c}{$\Delta E^{\ddagger}$} \\
cc-pVDZ & & 0.5 & 2.8 & 7.5 & 5.2 \\
cc-pVDZ-DK & & 0.5 & 2.7 & 7.4 & 5.1 \\
cc-pVDZ-PP & 10 & 0.4 & 2.6 & 7.3 & 5.0 \\
CRENBL & 18 & 0.7 & 3.2 & 8.4 & 5.9 \\
LANL2DZ & 28 & 0.8 & 3.1 & 7.9 & 5.0 \\
& & $\Delta E$ & & & \\
cc-pVDZ & & -19.6 & -17.8 & -15.7 & -18.1 \\
cc-pVDZ-DK & & -19.9 & -18.0 & -15.8 & -18.2 \\
cc-pVDZ-PP & 10 & -20.5 & -18.6 & -16.4 & -18.8 \\
CRENBL & 18 & -17.5 & -15.2 & -12.1 & -14.2 \\
LANL2DZ & 28 & -19.1 & -17.7 & -14.6 & -16.5
\end{tabular}

pseudopotentials (cc-pVNZ-PP, $\mathrm{N}=\mathrm{D}, \mathrm{T}, \mathrm{Q}$ ) of comparable quality due to the increased number of electrons as well as the need to account for relativistic effects. For the sake of brevity, we will occasionally refer to the correlation consistent basis sets simply as NZ and their pseudopotential analogs as NZ-PP. To account for relativistic effects for explicit all-electron basis sets, we use the first-order Douglas-Kroll-Hess formalism ${ }^{41}$ as implemented in Molpro 2006.1.42 The use of these DouglasKroll-Hess one-electron integrals with a correlation consistent basis set is designated by cc-pVNZ-DK. As demonstrated in Table 1, these small-core pseudopotentials give results that are very comparable with those from explicit all-electron basis sets of the same cardinal number for reaction 1 with $X=G e$, an atom for which relativistic effects are small. For an atom with an outermost shell of quantum number $n$, the cc-pVNZ-PP pseudopotentials explicitly treat the $n s p$ and $(n-1) s p d$ shells, leaving a core of 10, 28 and 60 electrons for germanium, tin and lead, respectively. In contrast, the LANL2DZ and SBKJC pseudopotentials have a larger core of 28,46 , and 78 electrons while CRENBL has 18,36 , and 68 core electrons for Ge, Sn and $\mathrm{Pb}$, respectively. ${ }^{43}$ Reaction barriers and energies can be rather sensitive to the choice of the pseudopotential, as shown in Table 1 (and as discussed further below). For basis sets of double- $\zeta$ quality, reaction barriers and energies predicted using the all-electron basis, the all-electron basis with first-order Douglas-Kroll relativistic correction, and the correlationconsistent pseudopotentials agree remarkably well for reaction 1 with Ge, while predictions using the large-core CRENBL and LANL2DZ deviate significantly, particularly for the case of the CRENBL ECP.

For cc-pVNZ or cc-pVNZ-PP basis sets which are designed to capture valence electron correlation, we employ the frozencore approximation. We freeze the $3 s^{2} 3 p^{6} 3 d^{10}, 4 s^{2} 4 p^{6} 4 d^{10}$ and $5 s^{2} 5 p^{6} 5 d^{10}$ "core" orbitals for $\mathrm{Ge}, \mathrm{Sn}$ and $\mathrm{Pb}$, respectively, even though correlating the outermost $d$ shell may be important in some cases. ${ }^{44}$ A limited analysis indicates that this core-freezing scheme does not introduce significant error but makes it possible to study larger systems using highly correlated methods.

Electron correlation is accounted for using second-order Møller-Plesset perturbation theory (MP2) and coupled-cluster theory with single, double, and perturbative triple substitutions $[\mathrm{CCSD}(\mathrm{T})] .{ }^{45}$ Computations employed the Molpro 2006.1 program. ${ }^{42}$ For open-shell systems, we use RMP2 ${ }^{46}$ and the partially spin-restricted CCSD(T), designated as ROHF-RCCSD(T) or simply RCCSD(T). ${ }^{47,48}$ Although we use restricted (ROHF) references, the $\left\langle\hat{S}^{2}\right\rangle$ values even for unrestricted (UHF) references indicate that spin contamination is very minimal in the systems considered. We have also employed the B3LYP 49 and BHLYP ${ }^{50,51}$ (also called BH\&HLYP) functionals as imple- 
mented in Molpro 2006.1. ${ }^{42}$ Because density functional theory (DFT) methods typically underestimate reaction barriers, especially for hydrogen transfer reactions (see ref 15 and references within), it is interesting to examine their performance for the present reactions. B3LYP and functionals using inexact exchange have been particularly susceptible to self-interaction errors that lead to the underestimation of barriers. Functionals such as BHLYP, ${ }^{50,51}$ which includes 50\% Hartree-Fock exchange (compared to $20 \%$ in B3LYP) and 50\% Becke88 exchange $^{52}$ in conjunction with the LYP correlation functional, ${ }^{50}$ perform better. (Of the many other exchange-correlation functionals designed to predict improved hydrogen transfer barriers, the MPW1 $\mathrm{K}^{53}$ functional has also had some success. $)^{54}$

To compare our theoretical heats of reaction $\Delta H(298 \mathrm{~K})$ directly with the experimental thermochemical data, we have converted our ab initio bare energy differences, $\Delta E$, into $0 \mathrm{~K}$ enthalpy differences, $\Delta H(0 \mathrm{~K})$, by adding the zero-point vibrational energy correction ( $\triangle \mathrm{ZPVE})$, estimated simply as onehalf of the sum of the (unscaled) vibrational frequencies. We also obtain $298 \mathrm{~K}$ enthalpy differences, $\Delta H(298 \mathrm{~K})$, by adding finite temperature corrections using the usual vibrational, rotational, and translational partition functions in conjunction with the harmonic oscillator, rigid rotator, and particle-in-abox models.

The phenomenological activation barriers, $E_{\mathrm{a}}$, are determined from experiment by an indirect process in which the reaction rate, $k$, is obtained at a series of temperatures, $T$. Fitting the temperature-dependent rate to a simple Arrhenius form, $k(T)=$ $A e^{-E_{a} / R T}$, the physical activation barrier can be determined. The problem with this approach is that most rate-vs-temperature relations do not fit the Arrhenius form for all temperature regimes due to effects such as hydrogen tunneling or the strong temperature dependence of the vibrational partition function when there are low-frequency bending modes. We compared our theoretical barriers with experimental values derived from rate-vs-temperature data in temperature ranges where a simple Arrhenius fit seems suitable. It must be stressed that these experimentally deduced activation barriers depend on the temperature range used for the Arrhenius fit and that this complicates a direct comparison with reaction barriers computed quantum mechanically.

To compare our "classical" activation barriers, $\Delta E^{\ddagger}$, with these experimentally deduced activation energies, $E_{\mathrm{a}}$, we first add zero-point vibrational corrections and finite-temperature corrections (as discussed above) to obtain $\Delta H^{\ddagger}(T)$. Next, it follows from transition state theory ${ }^{55}$ that for a reaction that undergoes a change of $\Delta n^{\ddagger}$ in the number of molecules while going from reactants to a transition state, the experimental $E_{\mathrm{a}}(T)$ is related to $\Delta H^{\ddagger}(\mathrm{T})$ by

$$
E_{\mathrm{a}}(T)=\Delta H^{\ddagger}(T)+\left(1-\Delta n^{\ddagger}\right) R T
$$

$\Delta n^{\ddagger}$ for these bimolecular reactions is -1 since the two reactants form one complex in the transition state.

One possible cause for a deviation from Arrhenius behavior is quantum mechanical tunneling of hydrogen atoms through classical barriers. The simplest approach to assess the role of quantum tunneling is the Wigner correction to the reaction rate. ${ }^{56,57}$ Given the magnitude $v_{t}$ of the imaginary frequency along the reaction coordinate at the transition state, the rate is enhanced by a factor of

$$
K_{\mathrm{W}}(T)=1+\frac{1}{24}\left(\frac{h v_{t}}{k_{\mathrm{b}} T}\right)^{2}
$$

Note that this correction predicts tunneling to be faster through thin barriers (with large $v_{t}$ ) than through wide barriers (small $v_{t}$ ), as one would expect. Because we are comparing activation energies rather than rates, we may incorporate this correction into our theoretical results as an effective barrier height lowering by evaluating

$$
\Delta E_{\mathrm{a}}=-k_{\mathrm{b}} \frac{\mathrm{d} \ln K_{\mathrm{W}}}{\mathrm{d}(1 / T)}=-2 k_{\mathrm{b}} T \frac{y(T)}{1+y(T)}
$$

where $y(T)=1 / 24\left(h v_{t} / k_{\mathrm{b}} T\right)^{2}$. As discussed below, this correction amounts to a few tenths of $1 \mathrm{kcal} \mathrm{mol}^{-1}$ for the systems studied. Wigner-corrected activation energies will be denoted $E_{\mathrm{a}}-\mathrm{W}$.

\section{Results and Discussion}

3.1. Transition State Geometries. As predicted by Hammond's postulate, ${ }^{58}$ reactions with a small barrier and high exothermicity have a transition state that closely resembles the reactants. In agreement with this prediction, for the four reactions studied, the transition state has more reactant-like geometry as the metal/metalloid changes from $\mathrm{Si}$ through $\mathrm{Pb}$, because there is an accompanying increase in the reaction exothermicity and decrease in barrier height. At the RMP2/cc$\mathrm{pVDZ}[-\mathrm{PP}]$ level, reactions involving $\mathrm{Pb}$ typically have low barriers $\left(\Delta E^{\ddagger}<4 \mathrm{kcal} \mathrm{mol}^{-1}\right)$ and high exothermicities $(\Delta E \sim$ -35 to $-45 \mathrm{kcal} \mathrm{mol}^{-1}$ ), and the $\mathrm{Pb}-\mathrm{H}$ bond lengths in the transition state $(R[\mathrm{~Pb}-\mathrm{H}] \sim 1.8 \AA)$ are very similar to what they are in the reactants $(\sim 1.8 \AA)$. Additionally, the forming bond between hydrogen and carbon (reactions 2-4) or hydrogen (reaction 1) is very long in the transition state: $R[\mathrm{C}-\mathrm{H}] \sim$ $1.8 \AA$ and $R[\mathrm{H}-\mathrm{H}] \sim 1.4 \AA$. This is in contrast to reactions involving $\mathrm{Si}$, for which $\Delta E^{\ddagger} \sim 8-11 \mathrm{kcal} \mathrm{mol}^{-1}, \Delta E \sim-9$ to $-19 \mathrm{kcal} \mathrm{mol}^{-1}$, and the transition state has geometrical parameters $R[\mathrm{Si}-\mathrm{H}] \sim 1.6 \AA$ (compared to $\sim 1.5 \AA$ in the reactant), $R[\mathrm{C}-\mathrm{H}] \sim 1.6$, and $R[\mathrm{H}-\mathrm{H}] \sim 1.1 \AA$.

3.2. Basis Set Dependence. The reliability of our predicted barriers and energies of reaction depends on the quality of the basis sets employed and the level of electron correlation treatment. In the case of the heavy group IVA atoms, it is important to properly account for relativistic effects, as well. Small-core pseudopotentials replace only a few core orbitals by a pseudopotential, whereas large-core pseudopotentials replace more core orbitals and leave few orbitals to be described explicitly by a self-consistent-field procedure. There is an apparent difference in the quality of predictions made using small-core and large-core pseudopotentials, as demonstrated in Table 1 for the reaction $\mathrm{H} \cdot+\mathrm{GeH}_{4} \rightarrow \mathrm{H}_{2}+\cdot \mathrm{GeH}_{3}$. The comparison was most convenient for a reaction involving $\mathrm{Ge}$ because there are explicit basis sets as well as pseudopotentials for germanium.

In Table 1, the most accurate representation should be the all-electron cc-pVDZ basis set with a first-order DouglasKroll-Hess relativistic correction, designated in the Table as cc-pVDZ-DK. Comparing the $\Delta E^{\ddagger}$ and $\Delta E$ values predicted by other basis sets and pseudopotentials with cc-pVDZ-DK values, the CRENBL and LANL2DZ ECPs deviate rather significantly. LANL2DZ and CRENBL are common pseudopotentials with a large core of 28 and 18 electrons, respectively. Although barriers and energies of reaction predicted by the small-core cc-pVDZ-PP match those of cc-pVDZ-DK almost exactly, the CRENBL and LANL2DZ analogs introduce an error as much as $\sim 1 \mathrm{kcal} \mathrm{mol}^{-1}$ for barriers and $\sim 4 \mathrm{kcal} \mathrm{mol}^{-1}$ for energies of reaction, even for this seemingly simple reaction. Compared to the all-electron, relativistic cc-pVDZ-DK results, it is 
TABLE 2: Basis Set and Method Dependence of Classical Energies of Activation $\left(\Delta E^{\ddagger}\right)$ and $\operatorname{Reaction}\left(\Delta E, \mathrm{kcal}^{\mathrm{mol}}{ }^{-1}\right)$ for $\mathrm{H}^{\cdot}+$ $\mathrm{XH}_{4} \rightarrow \mathrm{H}_{2}+\cdot \mathrm{XH}_{3}$, Where $\mathrm{X}=\mathrm{Si}$, Ge, Sn, or $\mathbf{P b}^{a, b}$

\begin{tabular}{|c|c|c|c|c|c|c|c|c|c|c|c|c|}
\hline & \multicolumn{6}{|c|}{$\Delta E^{\ddagger}$} & \multicolumn{6}{|c|}{$\Delta E$} \\
\hline & $\mathrm{DZ}$ & DZ-PP & $\mathrm{TZ}$ & TZ-PP & QZ & QZ-PP & $\mathrm{DZ}$ & DZ-PP & $\mathrm{TZ}$ & TZ-PP & $\mathrm{QZ}$ & $\overline{\text { QZ-PP }}$ \\
\hline \multicolumn{13}{|c|}{$\mathrm{X}=\mathrm{Si}$} \\
\hline B3LYP & 1.6 & - & 1.9 & - & 2.0 & - & -13.9 & - & -15.2 & - & -14.9 & - \\
\hline BHLYP & 4.7 & - & 5.1 & - & 5.2 & - & -12.4 & - & -13.1 & - & -12.7 & - \\
\hline MP2 & 9.6 & - & 8.6 & - & 8.4 & - & -10.0 & - & -11.1 & - & -10.7 & - \\
\hline $\operatorname{CCSD}(\mathrm{T})$ & 6.9 & - & 5.8 & - & 5.5 & - & -12.4 & - & -13.5 & - & -13.1 & - \\
\hline \multicolumn{13}{|c|}{$\mathrm{X}=\mathrm{Ge}$} \\
\hline B3LYP & 0.5 & 0.4 & 0.6 & 0.5 & & 0.5 & -19.6 & -20.5 & -21.5 & -22.4 & & -22.3 \\
\hline BHLYP & 2.8 & 2.6 & 2.9 & 2.7 & & 2.7 & -17.7 & -18.6 & -19.6 & -20.3 & & -20.2 \\
\hline MP2 & 7.5 & 7.3 & 6.2 & 6.2 & & 5.9 & -15.7 & -16.4 & -18.0 & -18.3 & & -18.4 \\
\hline $\operatorname{CCSD}(\mathrm{T})$ & 5.1 & 5.0 & 3.8 & 3.7 & & 3.3 & -18.1 & -18.8 & -20.2 & -20.5 & & -20.5 \\
\hline \multicolumn{13}{|c|}{$\mathrm{X}=\mathrm{Sn}$} \\
\hline B3LYP & - & 0.0 & - & 0.1 & - & 0.1 & & -29.5 & - & -31.8 & - & -31.5 \\
\hline BHLYP & - & 1.2 & - & 1.3 & - & 1.3 & & -27.6 & - & -29.7 & - & -29.5 \\
\hline MP2 & - & 5.5 & - & 4.4 & - & 4.1 & & -25.7 & - & -28.0 & - & -27.9 \\
\hline $\operatorname{CCSD}(\mathrm{T})$ & - & 3.6 & - & 2.3 & - & 2.0 & & -28.0 & - & -29.9 & - & -29.8 \\
\hline \multicolumn{13}{|c|}{$\mathrm{X}=\mathrm{Pb}$} \\
\hline B3LYP & - & 0.0 & - & 0.0 & - & 0.0 & - & -39.0 & - & -41.5 & - & -41.1 \\
\hline BHLYP & - & 0.4 & - & 0.4 & - & 0.4 & - & -36.9 & - & -39.2 & - & -38.8 \\
\hline MP2 & - & 3.9 & - & 2.9 & - & 2.2 & - & -34.9 & - & -37.4 & - & -37.2 \\
\hline $\operatorname{CCSD}(\mathrm{T})$ & - & 2.4 & - & 1.3 & - & & - & -37.3 & - & -39.5 & - & -39.2 \\
\hline
\end{tabular}

a “-” indicates the absence of a particular basis set or pseudopotential for the Group IVA element. ${ }^{b}$ DZ, TZ, and QZ denote cc-pVDZ, cc-pVTZ, and cc-pVQZ basis sets, respectively.

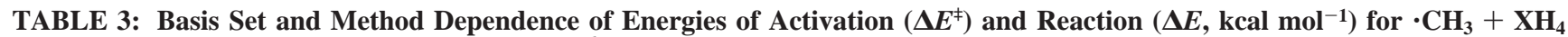
$\rightarrow \mathrm{CH}_{4}+\cdot \mathrm{XH}_{3}$, Where $\mathrm{X}=\mathrm{Si}, \mathrm{Ge}, \mathrm{Sn}$, or $\mathrm{Pb}^{a, b}$

\begin{tabular}{|c|c|c|c|c|c|c|c|c|c|c|c|c|}
\hline & \multicolumn{6}{|c|}{$\Delta E^{\ddagger}$} & \multicolumn{6}{|c|}{$\Delta E$} \\
\hline & $\mathrm{DZ}$ & DZ-PP & $\mathrm{TZ}$ & TZ-PP & $\mathrm{QZ}$ & QZ-PP & DZ & DZ-PP & $\mathrm{TZ}$ & TZ-PP & $\mathrm{QZ}$ & $\overline{\text { QZ-PP }}$ \\
\hline & & & & & & $\mathrm{X}=\mathrm{Si}$ & & & & & & \\
\hline B3LYP & 5.8 & - & 7.0 & - & 7.2 & - & -14.9 & - & -17.1 & - & -16.6 & - \\
\hline BHLYP & 10.2 & - & 11.4 & - & 11.7 & - & -16.4 & - & -15.2 & - & -14.7 & - \\
\hline MP2 & 10.4 & - & 9.8 & - & 9.7 & - & -18.5 & - & -17.9 & - & -17.3 & - \\
\hline $\operatorname{CCSD}(\mathrm{T})$ & 10.2 & - & 9.4 & - & & - & -16.8 & - & -16.5 & - & -16.0 & - \\
\hline $\begin{array}{l}\text { B3LYP } \\
\text { BHLYP } \\
\text { MP2 } \\
\text { CCSD(T) }\end{array}$ & $\begin{array}{l}3.5 \\
7.5 \\
8.2 \\
8.0\end{array}$ & $\begin{array}{l}3.1 \\
7.2 \\
8.0 \\
7.7\end{array}$ & $\begin{array}{l}4.3 \\
8.3 \\
7.2 \\
6.8\end{array}$ & $\begin{array}{l}4.0 \\
8.0 \\
7.6 \\
6.5\end{array}$ & & $\begin{array}{l}\mathrm{X}=\mathrm{Ge} \\
4.1 \\
8.1 \\
6.7 \\
6.2\end{array}$ & $\begin{array}{l}-20.6 \\
-21.8 \\
-24.2 \\
-22.5\end{array}$ & $\begin{array}{l}-21.5 \\
-22.6 \\
-24.9 \\
-23.2\end{array}$ & $\begin{array}{l}-23.4 \\
-21.8 \\
-24.7 \\
-23.1\end{array}$ & $\begin{array}{l}-24.4 \\
-22.5 \\
-25.1 \\
-23.5\end{array}$ & & $\begin{array}{l}-23.9 \\
-22.2 \\
-24.9 \\
-23.5\end{array}$ \\
\hline $\begin{array}{l}\text { B3LYP } \\
\text { BHLYP } \\
\text { MP2 } \\
\text { CCSD(T) }\end{array}$ & $\begin{array}{l}- \\
- \\
- \\
-\end{array}$ & $\begin{array}{l}1.7 \\
5.0 \\
6.3 \\
5.9\end{array}$ & $\begin{array}{l}- \\
- \\
- \\
-\end{array}$ & $\begin{array}{l}2.2 \\
5.5 \\
5.1 \\
4.4\end{array}$ & $\begin{array}{l}- \\
- \\
- \\
-\end{array}$ & $\begin{array}{l}\mathrm{X}=\mathrm{Sn} \\
2.4 \\
5.6 \\
4.8 \\
4.2\end{array}$ & $\begin{array}{l}- \\
- \\
- \\
-\end{array}$ & $\begin{array}{l}-30.4 \\
-31.6 \\
-34.3 \\
-32.4\end{array}$ & $\begin{array}{l}- \\
- \\
- \\
-\end{array}$ & $\begin{array}{l}-33.7 \\
-31.9 \\
-34.7 \\
-32.9\end{array}$ & $\begin{array}{l}- \\
- \\
- \\
-\end{array}$ & $\begin{array}{l}-33.2 \\
-31.4 \\
-34.4 \\
-32.7\end{array}$ \\
\hline $\begin{array}{l}\text { B3LYP } \\
\text { BHLYP } \\
\text { MP2 } \\
\text { CCSD(T) }\end{array}$ & $\begin{array}{l}- \\
- \\
-\end{array}$ & $\begin{array}{l}0.2 \\
2.6 \\
3.9 \\
3.5\end{array}$ & $\begin{array}{l}- \\
- \\
-\end{array}$ & $\begin{array}{l}0.5 \\
2.9 \\
2.8 \\
2.2\end{array}$ & $\begin{array}{l}- \\
- \\
- \\
-\end{array}$ & $\begin{array}{l}\mathrm{X}=\mathrm{Pb} \\
0.7 \\
3.1 \\
2.6 \\
2.0\end{array}$ & $\begin{array}{l}- \\
- \\
-\end{array}$ & $\begin{array}{l}-40.0 \\
-41.0 \\
-43.4 \\
-41.7\end{array}$ & $\begin{array}{l}- \\
- \\
- \\
-\end{array}$ & $\begin{array}{l}-43.4 \\
-41.4 \\
-44.2 \\
-42.4\end{array}$ & $\begin{array}{l}- \\
- \\
- \\
-\end{array}$ & $\begin{array}{l}-42.7 \\
-40.8 \\
-43.8 \\
-42.2\end{array}$ \\
\hline
\end{tabular}

a "--" indicates the absence of a particular basis set or pseudopotential for the Group IVA element. ${ }^{b}$ DZ, TZ, and QZ denote cc-pVDZ, cc-pVTZ, and cc-pVQZ basis sets, respectively.

particularly striking that the small-core CRENBL ECP does not even perform as well as the large-core LANL2DZ ECP. One should also note that the variation among predicted properties is more significant for MP2 and $\operatorname{CCSD}(\mathrm{T})$ than for the DFT methods. This observation is in line with the general basis set insensitivity of DFT.

Table 1 clearly shows that the cc-pVNZ-PP pseudopotentials are the most reliable of those considered. However, now that the cc-pVNZ and cc-pVNZ-PP families of basis sets have been chosen, it remains to be seen how the barriers and reaction energies depend on the basis set size as one progresses to tripleand quadruple- $\zeta$ basis sets. We can perform this analysis for reactions 1 and 2 , for which calculations using triple- $\zeta$ and quadruple- $\zeta$ quality basis sets are feasible. Tables 2 and 3 show that cc-pVDZ and cc-pVDZ-PP basis sets are not close to the complete basis set limit, as indicated by the significant difference between double- $\zeta$, triple- $\zeta$, and quadruple- $\zeta$ results. However, the convergence of activation energies with respect to basis set shows very different behavior for DFT as compared to ab initio methods such as MP2 and $\operatorname{CCSD}(\mathrm{T})$. Although activation energies predicted by ab initio methods typically decrease by $\sim 1 \mathrm{kcal} \mathrm{mol}^{-1}$ going from cc-pVDZ[-PP] to cc-pVTZ[-PP] and another $\sim 0.5 \mathrm{kcal} \mathrm{mol}^{-1}$ going from cc-pVTZ[-PP] to ccpVQZ[-PP], B3LYP and BHLYP show very small increases with increasing basis set size.

The sensitivity of the reaction energies $(\Delta E)$ to basis set is more similar between ab initio and DFT methods. For reactions 1 and 2 , reaction energies typically change by $\pm 3 \mathrm{kcal} \mathrm{mol}^{-1}$ 


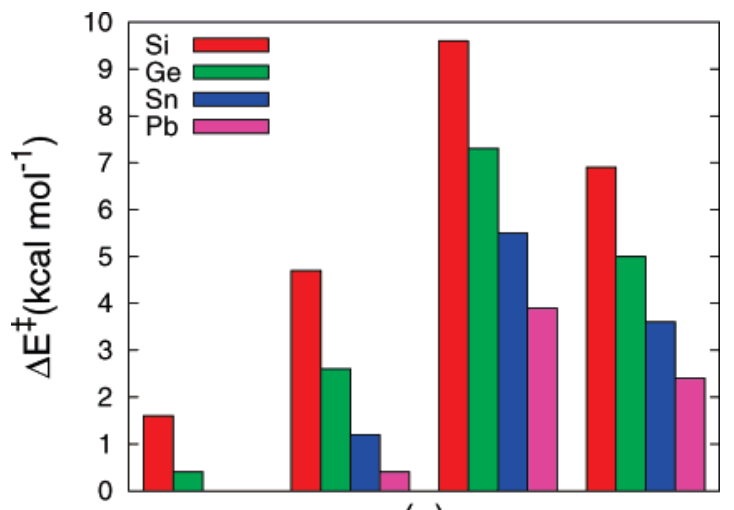

(a)

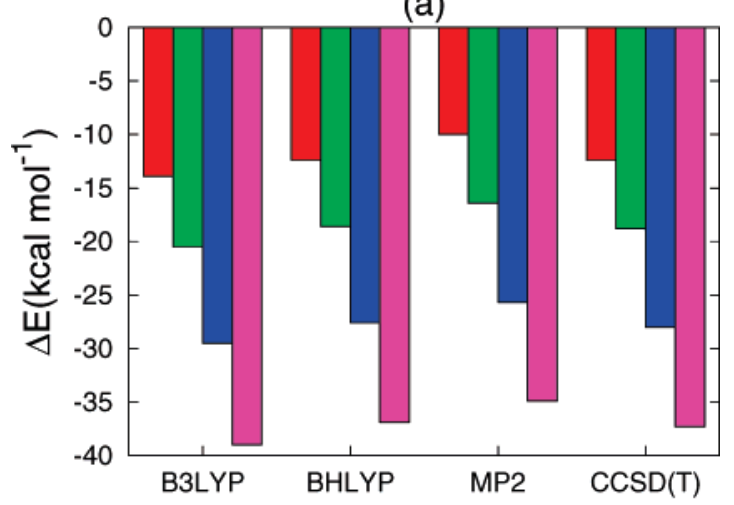

(b)

Figure 1. Classical barriers (a) and energies of reaction (b) for $\mathrm{H} \cdot+$ $\mathrm{XH}_{4} \rightarrow \mathrm{H}_{2}+\cdot \mathrm{XH}_{3}$ calculated using cc-pVDZ basis sets for $\mathrm{Si}$ and ccpVDZ-PP pseudopotential for $\mathrm{Ge}, \mathrm{Sn}$, and $\mathrm{Pb}$.

or less upon going from a double- $\zeta$ to a triple- $\zeta$ quality basis and by $0.7 \mathrm{kcal} \mathrm{mol}^{-1}$ or less by further improvement to quadruple- $\zeta$ basis sets. Given that the reaction energies are larger in magnitude than the activation barriers, these changes are small on a relative scale.

Overall, it appears that the cc-pVQZ[-PP] results, where available, are nearly converged with respect to the quality of the basis set. However, for the more limited cc-pVDZ[-PP] basis, which was more practical for the larger systems studied, one must keep in mind that a typical basis set correction is $\sim-1.5 \mathrm{kcal} \mathrm{mol}^{-1}$ for MP2 and $\operatorname{CCSD}(\mathrm{T})$ barriers just from increasing the basis set from cc-pVDZ[-PP] to cc-pVQZ[-PP] quality.

3.3. Dependence on Electron Correlation Treatment. Most density functionals underestimate hydrogen transfer barriers due to self-interaction error. This phenomenon is particularly notable in the case of pure functionals, such as BLYP, and it remains a significant problem in hybrid functionals with only a minor component of HF exchange, such as B3LYP. For example, B3LYP has difficulty predicting barriers for reactions involving atomic hydrogen, as demonstrated for the simple reaction $\mathrm{H}_{2}$ $+\mathrm{H} \rightarrow \mathrm{H}+\mathrm{H}_{2}$, for which UB3LYP/cc-pVDZ and RB3LYP/ cc-pVDZ classical barriers deviate from experiment by 6.7 and $4.9 \mathrm{kcal} \mathrm{mol}^{-1} .{ }^{15}$ Figures $1-4$ show the classical barriers and the reaction energies for the four reactions considered using different correlation methods in conjunction with the cc-pVDZ[PP] basis set. As seen in the figures, barriers computed using DFT differ from MP2 and CCSD(T) most significantly for reaction 1, for which B3LYP classical barriers are as much as $5 \mathrm{kcal} \mathrm{mol}^{-1}$ lower than $\operatorname{CCSD}(\mathrm{T})$ barriers. However, this deviation becomes smaller when we consider computations of the Wigner-corrected, $298 \mathrm{~K}$ activation energies using larger basis sets (differences typically $2 \mathrm{kcal} \mathrm{mol}^{-1}$ or less).
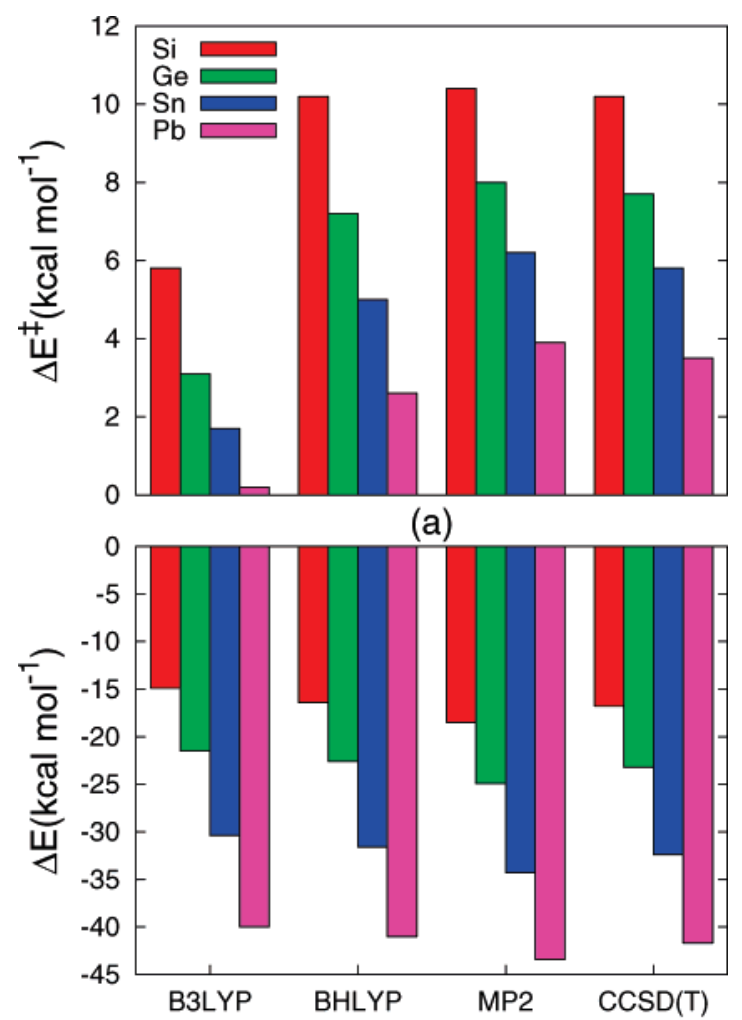

(b)

Figure 2. Classical barriers (a) and energies of reaction (b) for $\cdot \mathrm{CH}_{3}$ $+\mathrm{XH}_{4} \rightarrow \mathrm{CH}_{4}+\cdot \mathrm{XH}_{3}$ calculated using cc-pVDZ basis sets for $\mathrm{Si}$ and cc-pVDZ-PP pseudopotential for $\mathrm{Ge}, \mathrm{Sn}$, and $\mathrm{Pb}$.

For a set of hydrogen transfer reactions, $\mathrm{Hoz}$ et al. ${ }^{59}$ demonstrated that B3LYP barriers are usually lower than those from experiment and that the disparity between the two gets larger as the hydrogen donor or acceptor (or both) becomes more electronegative. For our systems, the electronegativity of the atoms increases in the order $\mathrm{Pb}(1.8)<\mathrm{Si}(1.90)<\mathrm{Sn}(1.96)<$ $\mathrm{Ge}(2.01)<\mathrm{H}(2.20)<\mathrm{C}(2.55) .{ }^{60}$ Since the electronegativities of our donor atoms $(\mathrm{Si}, \mathrm{Ge}, \mathrm{Sn}$, and $\mathrm{Pb})$ are fairly similar, we would expect B3LYP to perform comparably for them all. Our results do show that the performance of B3LYP as compared to $\operatorname{CCSD}(\mathrm{T})$ is roughly independent of the donor atom.

BHLYP, which contains 50\% HF exchange, is often thought to be superior to B3LYP for computing barrier heights because it is less prone to self-interaction error. Indeed, as shown in Figures $1-4$, the BHLYP barriers are significantly larger than the B3LYP barriers. For the cc-pVDZ[-PP] basis sets used in these figures, the BHLYP barriers are comparable to those predicted by MP2 and $\operatorname{CCSD}(\mathrm{T})$ for reactions 2 and 3, and they are significantly larger than the MP2 barriers for reaction 4 . For reactions 2-4, BHLYP barriers are frequently larger than MP2 and $\operatorname{CCSD}(\mathrm{T})$ barriers when larger basis sets are considered.

MP2 has a tendency to overestimate barriers relative to $\operatorname{CCSD}(\mathrm{T})$ for hydrogen transfer reactions between simple hydrocarbons, ${ }^{15}$ and that same pattern is observed here. This overestimation is most pronounced for reaction 1. These deviations of MP2 from CCSD(T) highlight the importance of the correlation treatment to obtain accurate barrier heights and reaction energies.

The reaction energies show significant dependence on the electron correlation treatment. For reaction 1, B3LYP reaction energies are lower than for all other methods by $1.5-4 \mathrm{kcal}$ $\mathrm{mol}^{-1}$, whereas MP2 predicts $\Delta E$ values that are $1-5 \mathrm{kcal} \mathrm{mol}^{-1}$ 


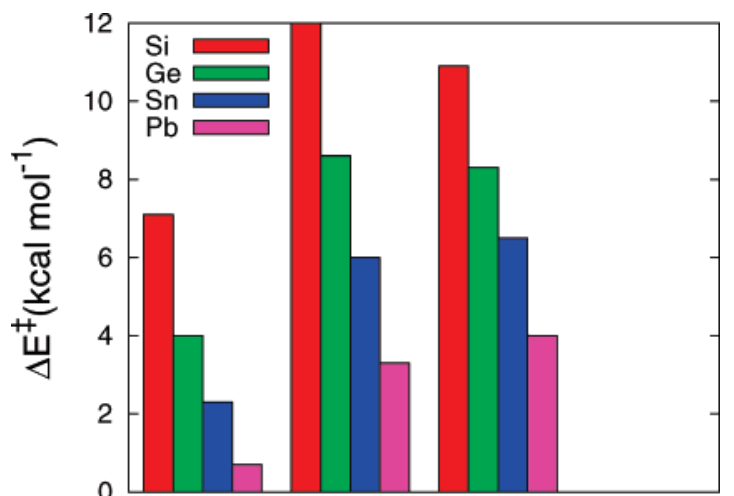

(a)

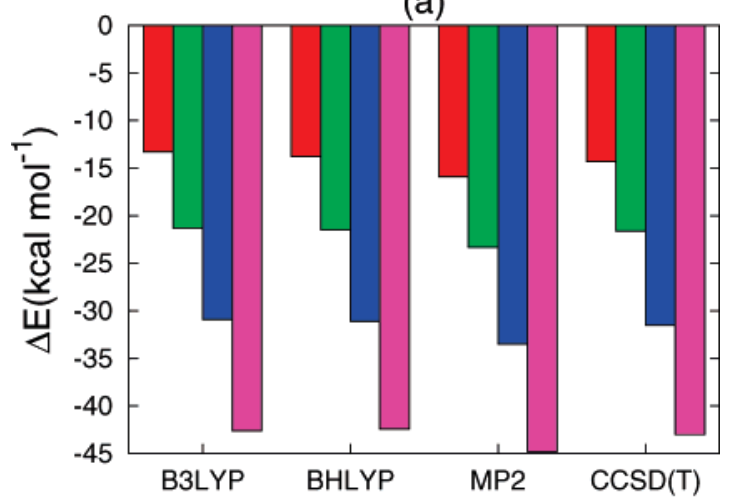

(b)

Figure 3. Classical barriers (a) and energies of reaction (b) for $\cdot \mathrm{CH}_{3}$ $+\mathrm{HX}\left(\mathrm{CH}_{3}\right)_{3} \rightarrow \mathrm{CH}_{4}+\cdot \mathrm{X}\left(\mathrm{CH}_{3}\right)_{3}$ calculated using cc-pVDZ basis sets for $\mathrm{Si}$ and cc-pVDZ-PP pseudopotential for $\mathrm{Ge}, \mathrm{Sn}$, and $\mathrm{Pb}$.

lower than all other methods for reactions $2-4$. Relative to CCSD(T), MP2 energies of reaction are typically $2 \mathrm{kcal} \mathrm{mol}^{-1}$ higher than those predicted by $\operatorname{CCSD}(\mathrm{T})$ for reaction 1 and $2 \mathrm{kcal} \mathrm{mol}^{-1}$ lower for reactions 2-4.

3.4. Comparison to Experimental Energies. Experimental enthalpies of reaction were calculated as the difference in the hydride bond dissociation energy, $D_{0}^{298}$, between the hydrogen donating and accepting groups. For a reaction of type

$$
\mathrm{Y} \cdot+\mathrm{HX} \rightarrow \mathrm{YH}+\cdot \mathrm{X}
$$

the $\Delta H(298)$ is calculated as

$$
\Delta H(298)=D_{0}^{298}(X-H)-D_{0}^{298}(Y-H)
$$

$D_{0}^{298}$ values for the relevant silicon and germanium species are available. ${ }^{60}$ Let us first consider the silicon-based reactions, whose energetics are presented in Table 4. Compared to the experimental reaction enthalpy $\Delta H(298)=-12.5 \mathrm{kcal} \mathrm{mol}^{-1}$ for reaction 1, the errors in quadruple- $\zeta$ B3LYP, BHLYP, MP2, and $\operatorname{CCSD}(\mathrm{T})$ values are $-1.8,0.4,2.5$, and $0.8 \mathrm{kcal} \mathrm{mol}^{-1}$, respectively. For reaction 2, with an experimental reaction enthalpy of $-13.3 \mathrm{kcal} \mathrm{mol}^{-1}$, the errors are $-0.3,1.8,-0.9$, and $1.2 \mathrm{kcal} \mathrm{mol}^{-1}$ for B3LYP, BHLYP, MP2, and CCSD(T), respectively. For reaction 3 (experimental enthalpy of $-10.4 \mathrm{kcal} \mathrm{mol}^{-1}$ ), theoretical results using the smaller cc-pVDZ basis are within $0.5 \mathrm{kcal} \mathrm{mol}^{-1}$, except for the case of MP2, for which the difference amounts to $2.0 \mathrm{kcal} \mathrm{mol}^{-1}$. The experimental enthalpy for reaction 4 is much smaller, at -1.1 $\mathrm{kcal} \mathrm{mol}^{-1}$. In this case, the DFT enthalpies are in good agreement (within $0.4 \mathrm{kcal} \mathrm{mol}^{-1}$ ), but MP2 and $\operatorname{CCSD}(\mathrm{T})$ are somewhat further off for the cc-pVDZ basis set (errors of 5.1 and $3.0 \mathrm{kcal} \mathrm{mol}^{-1}$, respectively, with basis set effects probably being the largest contributor to the difference).

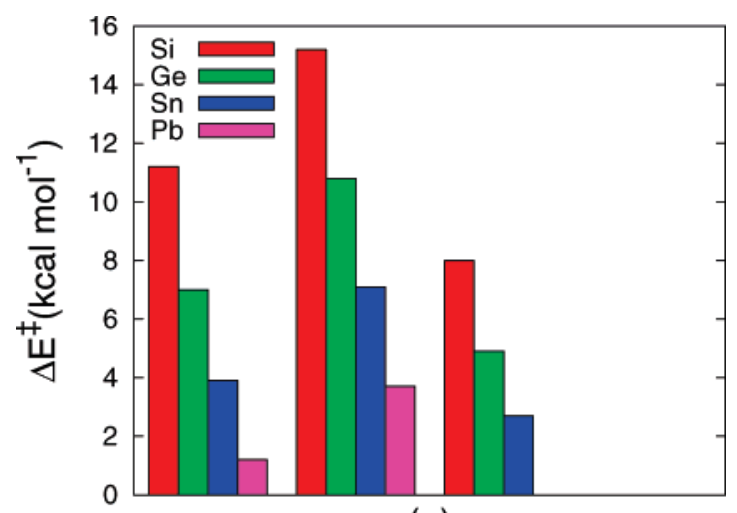

(a)

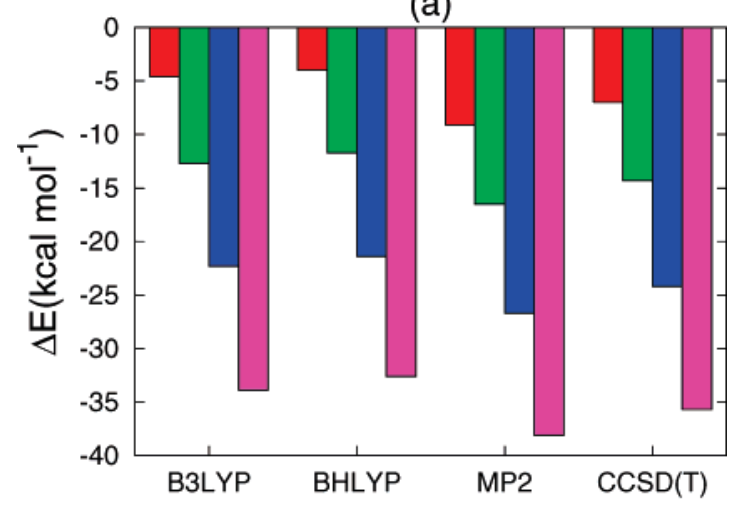

(b)

Figure 4. Classical barriers (a) and energies of reaction (b) for $\cdot \mathrm{C}\left(\mathrm{CH}_{3}\right)_{3}+\mathrm{HX}\left(\mathrm{CH}_{3}\right)_{3} \rightarrow \mathrm{HC}\left(\mathrm{CH}_{3}\right)_{3}+\cdot \mathrm{X}\left(\mathrm{CH}_{3}\right)_{3}$ calculated using ccpVDZ basis sets for Si and cc-pVDZ-PP pseudopotential for Ge, Sn, and $\mathrm{Pb}$.

The comparisons between theory and experiment for the germanium-based reactions (Table 5) exhibit a behavior that is similar to those seen for the silicon-based reactions. For reaction 1 , the difference between experiment and theory (using the ccpVQZ-PP pseudopotential) is $<1.4 \mathrm{kcal} \mathrm{mol}^{-1}$, except for the case of MP2, for which it is $3.3 \mathrm{kcal} \mathrm{mol}^{-1}$. For reaction 2, B3LYP, BHLYP, MP2, and CCSD(T) deviate from experiment by $0.9,2.8,0.0$, and $1.4 \mathrm{kcal} \mathrm{mol}^{-1}$, respectively. Just as the case for silicon-based reaction 3 , the only notable difference between experiment and theory (using the cc-pVDZ-PP pseudopotential) appears for MP2/DZ-PP, for which it is $-2.1 \mathrm{kcal}$ $\mathrm{mol}^{-1}$. The reaction enthalpy for reaction 4 is larger $(-8.7 \mathrm{kcal}$ $\mathrm{mol}^{-1}$ ) for germanium than it was for silicon, but again, the comparisons between theory and experiment are similar: there are small errors vs experiment for B3LYP $(-0.6)$ and BHLYP (0.3) and larger errors for MP2 (-4.7) and $\operatorname{CCSD}(\mathrm{T})$ $\left(-2.5 \mathrm{kcal} \mathrm{mol}^{-1}\right)$ using double- $\zeta$ basis sets. Overall, this level of agreement for these reaction energies appears reasonable.

As mentioned in Section 2, it is often difficult to match the phenomenological activation barriers that are derived from experiment with those computed theoretically. Our high-level Wigner-corrected CCSD(T)/cc-pVTZ[-PP] and CCSD(T)/ccpVQZ[-PP] barriers for reactions 1 and 2 differ from experiment by $0.8-3.3 \mathrm{kcal} \mathrm{mol}^{-1}$ for the few cases for which experimental barriers were available for comparison. This agreement is reasonable, given the inherent difficulties of making these comparisons, but given the large basis sets used and the presumed robustness of the $\operatorname{CCSD}(\mathrm{T})$ method for these systems, one might have expected somewhat closer agreement. Surprisingly, B3LYP barriers match the available experimental values better than any of the other methods.

From a theoretical standpoint, the potential remaining sources of error include the approximate nature of the Wigner tunneling 
TABLE 4: Energies of Activation $\left(\Delta E^{\ddagger}\right)$ and Reaction $\left(\Delta E, \mathrm{kcal} \mathrm{mol}^{-1}\right)$ for Silicon-Based Reactions ${ }^{a, b}$

\begin{tabular}{|c|c|c|c|c|c|c|c|c|c|c|c|c|c|}
\hline & \multicolumn{3}{|c|}{ B3LYP } & \multicolumn{3}{|c|}{ BHLYP } & \multicolumn{3}{|c|}{ MP2 } & \multicolumn{3}{|c|}{$\operatorname{CCSD}(\mathrm{T})$} & \multirow[b]{2}{*}{ expt } \\
\hline & DZ & $\mathrm{TZ}$ & QZ & $\mathrm{DZ}$ & $\mathrm{TZ}$ & QZ & $\mathrm{DZ}$ & $\mathrm{TZ}$ & QZ & DZ & $\mathrm{TZ}$ & QZ & \\
\hline \multicolumn{14}{|c|}{$\cdot \mathrm{H}+\mathrm{SiH}_{4} \rightarrow \mathrm{H}_{2}+\cdot \mathrm{SiH}_{3}$} \\
\hline$\Delta E^{\ddagger}$ & 1.6 & 1.9 & 2.0 & 4.7 & 5.1 & 5.2 & 9.6 & 8.6 & 8.4 & 6.9 & 5.8 & 5.5 & \\
\hline$\Delta H^{\ddagger}(0)$ & 1.2 & 1.5 & 1.6 & 4.0 & 4.4 & 4.5 & 8.8 & 7.8 & 7.6 & 7.0 & 5.9 & 5.6 & \\
\hline$\Delta H^{\ddagger}(298)$ & 0.9 & 1.2 & 1.3 & 3.6 & 4.0 & 4.1 & 8.5 & 7.5 & 7.3 & 6.7 & 5.6 & 5.3 & \\
\hline$E_{\mathrm{a}}(298)$ & 2.1 & 2.4 & 2.5 & 4.8 & 5.2 & 5.3 & 9.7 & 8.7 & 8.5 & 7.8 & 6.8 & 6.5 & \\
\hline$E_{\mathrm{a}}(298)-\mathrm{W}$ & 1.8 & 2.1 & 2.2 & 4.1 & 4.5 & 4.6 & 8.7 & 7.7 & 7.5 & 7.1 & 6.1 & 5.8 & $2.5-3.8^{c}$ \\
\hline$\Delta E$ & -13.9 & -15.2 & -14.9 & -12.4 & -13.1 & -12.7 & -10.0 & -11.1 & -10.7 & -12.4 & -13.5 & -13.1 & \\
\hline$\Delta H(0)$ & -13.9 & -15.2 & -14.9 & -12.4 & -13.1 & -12.7 & -9.9 & -11.0 & -10.6 & -11.6 & -12.7 & -12.3 & \\
\hline$\Delta H(298)$ & -13.3 & -14.6 & -14.3 & -11.8 & -12.5 & -12.1 & -9.3 & -10.4 & -10.0 & -11.0 & -12.1 & -11.7 & $-12.5^{d}$ \\
\hline \multicolumn{14}{|c|}{$\cdot \mathrm{CH}_{3}+\mathrm{SiH}_{4} \rightarrow \mathrm{CH}_{4}+\cdot \mathrm{SiH}_{3}$} \\
\hline$\Delta E^{q}$ & 5.8 & 7.0 & 7.2 & 10.2 & 11.4 & 11.7 & 10.4 & 9.8 & 9.7 & 10.2 & 9.4 & & \\
\hline$\Delta H^{\ddagger}(0)$ & 6.1 & 7.3 & 7.5 & 10.7 & 11.9 & 12.2 & 10.6 & 10.0 & 9.9 & 11.4 & 10.6 & & \\
\hline$\Delta H^{\ddagger}(298)$ & 4.9 & 6.1 & 6.3 & 9.3 & 10.5 & 10.8 & 9.6 & 9.0 & 8.9 & 9.4 & 8.6 & & \\
\hline$E_{\mathrm{a}}(298)$ & 6.1 & 7.3 & 7.5 & 10.5 & 11.7 & 12.0 & 10.8 & 10.2 & 10.1 & 10.6 & 9.8 & & \\
\hline$E_{\mathrm{a}}(298)-\mathrm{W}$ & 5.6 & 6.8 & 7.0 & 9.7 & 10.9 & 11.2 & 10.0 & 9.4 & 9.3 & 9.8 & 9.0 & & $6.2-7.5^{e}$ \\
\hline$\Delta E$ & -14.9 & -17.1 & -16.6 & -16.4 & -15.2 & -14.7 & -18.5 & -17.9 & -17.3 & -16.8 & -16.5 & -16.0 & \\
\hline$\Delta H(0)$ & -11.7 & -13.9 & -13.4 & -13.0 & -11.8 & -11.3 & -15.2 & -14.6 & -14.0 & -12.7 & -12.4 & -11.9 & \\
\hline$\Delta H(298)$ & -11.9 & -14.1 & -13.6 & -13.2 & -12.0 & -11.5 & -15.4 & -14.8 & -14.2 & -12.9 & -12.6 & -12.1 & $-13.3^{d}$ \\
\hline \multicolumn{14}{|c|}{$\cdot \mathrm{CH}_{3}+\mathrm{HSi}\left(\mathrm{CH}_{3}\right)_{3} \rightarrow \mathrm{CH}_{4}+\cdot \mathrm{Si}\left(\mathrm{CH}_{3}\right)_{3}$} \\
\hline$\Delta E^{\neq}$ & 7.1 & & & 12.0 & & & 10.9 & & & & & & \\
\hline$\Delta H^{\ddagger}(0)$ & 7.1 & & & 12.2 & & & 12.0 & & & & & & \\
\hline$\Delta H^{\ddagger}(298)$ & 6.7 & & & 11.8 & & & 11.6 & & & & & & \\
\hline$E_{\mathrm{a}}(298)$ & 7.9 & & & 13.0 & & & 12.8 & & & & & & \\
\hline$E_{\mathrm{a}}(298)-\mathrm{W}$ & 7.3 & & & 12.1 & & & 11.9 & & & & & & $7.0-8.3^{f}$ \\
\hline$\Delta E$ & -13.3 & & & -13.8 & & & -15.9 & & & -14.3 & & & \\
\hline$\Delta H(0)$ & -9.7 & & & -9.9 & & & -12.2 & & & -10.5 & & & \\
\hline$\Delta H(298)$ & -9.9 & & & -10.1 & & & -12.4 & & & -10.7 & & & $-10.4^{d}$ \\
\hline \multicolumn{14}{|c|}{$\cdot \mathrm{C}\left(\mathrm{CH}_{3}\right)_{3}+\mathrm{HSi}\left(\mathrm{CH}_{3}\right)_{3} \rightarrow \mathrm{HC}\left(\mathrm{CH}_{3}\right)_{3}+\cdot \mathrm{Si}\left(\mathrm{CH}_{3}\right)_{3}$} \\
\hline$\Delta E^{\ddagger}$ & 11.2 & & & 15.2 & & & 8.0 & & & & & & \\
\hline$\Delta H^{\ddagger}(0)$ & 10.4 & & & 14.5 & & & $7.3^{g}$ & & & & & & \\
\hline$\Delta H^{\ddagger}(298)$ & 10.6 & & & 14.6 & & & $7.4^{g}$ & & & & & & \\
\hline$E_{\mathrm{a}}(298)$ & 11.8 & & & 15.8 & & & $8.6^{g}$ & & & & & & \\
\hline$E_{\mathrm{a}}(298)-\mathrm{W}$ & 11.0 & & & 14.9 & & & 7.78 & & & & & & \\
\hline & -4.6 & & & -4.0 & & & -9.1 & & & -7.0 & & & \\
\hline$\Delta H(0)$ & -1.1 & & & -0.4 & & & -5.8 & & & $-3.6^{h}$ & & & \\
\hline$\Delta H(298)$ & -1.5 & & & -0.8 & & & -6.2 & & & $-4.1^{h}$ & & & $-1.1^{d}$ \\
\hline
\end{tabular}

${ }^{a}$ All ZPVE, thermal, and Wigner tunneling corrections evaluated using cc-pVDZ basis unless indicated otherwise. ${ }^{b} \mathrm{DZ}$, TZ, and QZ denote cc-pVDZ, cc-pVTZ, and cc-pVQZ basis sets, respectively. ${ }^{c} \operatorname{Ref} 69-71 .{ }^{d} \operatorname{Ref} 60 .{ }^{e}$ Ref $72-76 .{ }^{f} \operatorname{Ref} 72,76-78 .{ }^{g}$ Thermal, ZPVE, and Wigner corrections computed using BHLYP frequencies. ${ }^{h}$ Thermal and ZPVE corrections computed using MP2 frequencies.

correction, the possible need for diffuse functions in the basis, our core-freezing scheme, the approximations used in the estimation of the finite temperature corrections, and the potential for multireference character in the wavefunction. In addition to theoretical errors, there remains the previously mentioned uncertainty in the experimentally deduced barriers due to possible non-Arrhenius behavior and the fact that the fitting procedure is sensitive to the temperature range used.

Let us consider the most likely potential sources of error in the theoretical treatment and how agreement with experiment might be improved. When using a double- $\zeta$ quality basis set in MP2 and CCSD(T) calculations, the effect of diffuse functions is seen to be as much as $2 \mathrm{kcal} \mathrm{mol}^{-1}$ for classical activation barriers (see Supporting Information). For the more complete triple- and quadruple- $\zeta$ quality basis sets, the difference remains significant but decreases to well below $1 \mathrm{kcal} \mathrm{mol}^{-1}$. Thus, the need for diffuse functions could account in part for the difference between experimental and theoretical activation barriers. Another possible source of error could be our core-freezing scheme. For cc-pVNZ and cc-pVNZ-PP basis sets, we did not correlate electrons in the highest-lying set of $d$ orbitals. Although this approximation appears reasonable, ${ }^{39}$ it is possible that correlating these electrons may be important. To explore this question, MP2 and $\operatorname{CCSD}(\mathrm{T})$ computations using the cc-pVDZ-PP basis were performed for reactions 1 and 2 in which the $(n-1) \mathrm{d}$ shell was correlated. This led to a lowering of $0-0.1 \mathrm{kcal} \mathrm{mol}^{-1}$ for reaction 1 and $0.1-0.3 \mathrm{kcal} \mathrm{mol}^{-1}$ for reaction 2 , with a smaller effect for CCSD(T) than for MP2. Thus, the effect of d-electron correlation does not appear to be large.

Another potential source of error is the possible importance of electronic near-degeneracies in some of these systems. Whereas $\operatorname{CCSD}(\mathrm{T})$ is very reliable for well-behaved systems, it can suffer in the case of electronic near-degeneracies, as may arise in bond-breaking and bond-making situations. In an examination of reactions 1 and 2, we found that several of the transition states feature values of the $T_{1}$ diagnostic ${ }^{61,62}$ close to the value of 0.02 , above which multireference character often becomes important. Considering the alternative $\mathrm{D}_{1}$ diagnostic $^{63-65}$ for these systems, we find several values for transition states that approach 0.05 , whereas for open-shell systems such as those considered here, the quality of the coupled-cluster wavefunction is thought to degrade for values over 0.025. ${ }^{64}$ However, examination of the largest $\mathrm{T}_{2}$ amplitudes does not support the idea that nondynamical correlation effects could be large: the largest $\mathrm{T}_{2}$ amplitudes observed are in the range of $0.05-0.06$ for transition states, as compared to 0.05 for the well-behaved case of the $\mathrm{H}_{2} \mathrm{O}$ molecule (CCSD/6-31G). Moreover, preliminary full $\mathrm{CI} / 6-31 \mathrm{G}^{*}$ computations at $\mathrm{CCSD}(\mathrm{T}) / 6-31 \mathrm{G}^{*}$ geom- 
TABLE 5: Energies of Activation $\left(\Delta E^{\ddagger}\right)$ and Reaction $\left(\Delta E, \mathrm{kcal} \mathrm{mol}^{-1}\right)$ for Germanium-Based Reactions ${ }^{a, b}$

\begin{tabular}{|c|c|c|c|c|c|c|c|c|c|c|c|c|c|}
\hline & \multicolumn{3}{|c|}{ B3LYP } & \multicolumn{3}{|c|}{ BHLYP } & \multicolumn{3}{|c|}{ MP2 } & \multicolumn{3}{|c|}{$\operatorname{CCSD}(\mathrm{T})$} & \multirow[b]{2}{*}{ expt } \\
\hline & $\overline{\mathrm{DZ}-\mathrm{PP}}$ & TZ-PP & $\overline{\text { QZ-PP }}$ & $\overline{\mathrm{DZ}-\mathrm{PP}}$ & TZ-PP & $\overline{\text { QZ-PP }}$ & $\overline{\mathrm{DZ}-\mathrm{PP}}$ & TZ-PP & QZ-PP & DZ-PP & TZ-PP & QZ-PP & \\
\hline \multicolumn{14}{|c|}{$\cdot \mathrm{H}+\mathrm{GeH}_{4} \rightarrow \mathrm{H}_{2}+\cdot \mathrm{GeH}_{3}$} \\
\hline$\Delta E^{\ddagger}$ & 0.4 & 0.5 & 0.5 & 2.6 & 2.7 & 2.7 & 7.3 & 6.2 & 5.9 & 5.0 & 3.7 & 3.3 & \\
\hline$\Delta H^{\ddagger}(0)$ & 0.5 & 0.6 & 0.5 & 2.2 & 2.3 & 2.3 & 6.8 & 5.7 & 5.4 & 4.4 & 3.1 & 2.7 & \\
\hline$\Delta H^{\ddagger}(298)$ & 0.3 & 0.4 & 0.4 & 1.9 & 2.0 & 2.0 & 6.4 & 5.3 & 5.0 & 4.2 & 2.9 & 2.5 & \\
\hline$E_{\mathrm{a}}(298)$ & 1.5 & 1.6 & 1.6 & 3.1 & 3.2 & 3.2 & 7.6 & 6.5 & 6.2 & 5.3 & 4.1 & 3.7 & \\
\hline$E_{\mathrm{a}}(298)-\mathrm{W}$ & 1.4 & 1.5 & 1.5 & 2.6 & 2.7 & 2.7 & 6.8 & 5.7 & 5.4 & 4.7 & 3.5 & 3.1 & $1.8^{-2.3^{c}}$ \\
\hline$\Delta E$ & -20.5 & -22.4 & -22.3 & -18.6 & -20.3 & -20.2 & -16.4 & -18.3 & -18.4 & -18.8 & -20.5 & -20.5 & \\
\hline$\Delta H(0)$ & -20.3 & -22.2 & -22.1 & -18.3 & -20.0 & -19.9 & -16.0 & -17.9 & -18.0 & -18.6 & -20.3 & -20.3 & \\
\hline$\Delta H(298)$ & -19.7 & -21.6 & -21.5 & -17.8 & -19.5 & -19.4 & -15.5 & -17.4 & -17.5 & -18.0 & -19.7 & -19.7 & $-20.8^{d}$ \\
\hline \multicolumn{14}{|c|}{$\cdot \mathrm{CH}_{3}+\mathrm{GeH}_{4} \rightarrow \mathrm{CH}_{4}+\cdot \mathrm{GeH}_{3}$} \\
\hline$\Delta E^{\ddagger}$ & 3.1 & 4.0 & 4.1 & 7.2 & 8.0 & 8.1 & 8.0 & 7.6 & 6.7 & 7.7 & 6.5 & 6.2 & \\
\hline $\overrightarrow{\Delta H}(0)$ & 3.8 & 4.7 & 4.8 & 7.8 & 7.4 & 7.5 & 8.3 & 7.9 & 7.0 & 8.0 & 6.9 & 6.6 & \\
\hline$\Delta H^{\ddagger}(298)$ & 3.0 & 3.9 & 4.0 & 7.0 & 6.6 & 6.7 & 7.5 & 7.1 & 6.2 & 7.2 & 6.1 & 5.8 & \\
\hline$E_{\mathrm{a}}(298)$ & 4.2 & 5.1 & 5.2 & 8.1 & 7.7 & 7.8 & 8.7 & 8.3 & 7.4 & 8.4 & 7.3 & 7.0 & \\
\hline$E_{\mathrm{a}}(298)-\mathrm{W}$ & 4.0 & 4.9 & 5.0 & 7.5 & 7.1 & 7.2 & 8.0 & 7.6 & 6.7 & 7.7 & 6.6 & 6.3 & $\Delta E$ \\
\hline$\Delta E$ & -21.5 & -24.4 & -23.9 & -22.6 & -22.5 & -22.2 & -24.9 & -25.1 & -24.9 & -23.2 & -23.5 & -23.5 & \\
\hline$\Delta H(0)$ & -18.1 & -21.0 & -20.5 & -19.0 & -18.9 & -18.6 & -21.4 & -21.6 & -21.4 & -19.7 & -20.0 & -20.0 & \\
\hline$\Delta H(298)$ & -18.3 & -21.2 & -20.7 & -19.2 & -19.1 & -18.8 & -21.6 & -21.8 & -21.6 & -19.9 & -20.2 & -20.2 & $-21.6^{d}$ \\
\hline \multirow{2}{*}{\multicolumn{14}{|c|}{$\cdot \mathrm{CH}_{3}+\mathrm{HGe}\left(\mathrm{CH}_{3}\right)_{3} \rightarrow \mathrm{CH}_{4}+\cdot \mathrm{Ge}\left(\mathrm{CH}_{3}\right)_{3}$}} \\
\hline$\Delta E^{\ddagger}$ & 4.0 & & & 8.6 & & & & & & & & & \\
\hline$\Delta H^{\ddagger}(0)$ & 4.3 & & & 8.8 & & & 8.4 & & & & & & \\
\hline$\Delta H^{\ddagger}(298)$ & 3.9 & & & 8.3 & & & 7.9 & & & & & & \\
\hline$E_{\mathrm{a}}(298)$ & 5.1 & & & 9.5 & & & 9.1 & & & & & & \\
\hline$E_{\mathrm{a}}(298)-\mathrm{W}$ & 4.8 & & & 8.8 & & & 8.4 & & & & & & \\
\hline$\Delta E$ & -21.3 & & & -21.5 & & & -23.3 & & & -21.6 & & & \\
\hline$\Delta H(0)$ & -17.5 & & & -17.6 & & & -19.7 & & & $-18.0^{e}$ & & & \\
\hline$\Delta H(298)$ & -18.0 & & & -18.1 & & & -20.1 & & & $-18.4^{e}$ & & & $-18.0^{d}$ \\
\hline \multirow{2}{*}{\multicolumn{14}{|c|}{$\underset{10.8}{\cdot C}\left(\mathrm{CH}_{3}\right)_{3}+\mathrm{HGe}\left(\mathrm{CH}_{3}\right)_{3} \rightarrow \underset{4.9}{\mathrm{HC}\left(\mathrm{CH}_{3}\right)_{3}+\cdot \mathrm{Ge}\left(\mathrm{CH}_{3}\right)_{3}}$}} \\
\hline$\Delta E^{+}$ & & & & & & & & & & & & & \\
\hline$\Delta E$ & -12.7 & & & -11.7 & & & -16.5 & & & -14.3 & & & \\
\hline$\Delta H(0)$ & -8.9 & & & -7.9 & & & -13.0 & & & $-10.8^{e}$ & & & \\
\hline$\Delta H(298)$ & -9.3 & & & -8.4 & & & -13.4 & & & $-11.2^{e}$ & & & $-8.7^{d}$ \\
\hline
\end{tabular}

a All ZPVE, thermal, and Wigner tunneling corrections evaluated using cc-pVDZ basis unless indicated otherwise. ${ }^{b} \mathrm{DZ}, \mathrm{TZ}$, and QZ denote cc-pVDZ, cc-pVTZ, and cc-pVQZ basis sets,respectively ${ }^{c}$ Ref $79-81 .{ }^{d}$ Ref $60 .{ }^{e}$ Thermal and ZPVE corrections computed using MP2 frequencies.

etries for the reaction of $\mathrm{H}$ with $\mathrm{SiH}_{4}$ indicate a lowering of the classical barrier by a modest 0.3 out of a $10.9 \mathrm{kcal} \mathrm{mol}^{-1}$ barrier at the $\operatorname{CCSD}(\mathrm{T}) / 6-31 \mathrm{G}^{*}$ level of theory. Altogether, it appears that nondynamical correlation effects are not very significant and that $\operatorname{CCSD}(\mathrm{T})$ should be reliable for these reactions.

From an experimental standpoint, the kinetics data was gathered at a temperature regime different from $298 \mathrm{~K}$. Considering that activation barriers are inherently sensitive to temperature, it is possible that the choice of temperature regime could account for some of the discrepancy between our values and that of experiment. However, the experimental barriers we report are generated by fitting kinetics data from different experiments over various temperature ranges, and they represent the best fit. Our attempt to fit limited sets of data in the proximity of $298 \mathrm{~K}$ yielded barriers that are not very different from those inferred by fitting kinetics data over a much larger temperature range. Thus, the reason for the somewhat larger than expected difference between the experimentally deduced activation barriers and our best $\operatorname{CCSD}(\mathrm{T})$ results remains uncertain, and it would be interesting to examine this question with even more rigorous computations in the future. However, even if the errors in our best theoretical estimates are as large as $\sim 3 \mathrm{kcal} \mathrm{mol}^{-1}$ for reaction barriers, this is more than sufficient to obtain a qualitative and even semiquantitative understanding of these reactions.

It is clear from the theoretical predictions that the barriers for the reactions considered are quite small, with most of the MP2 and CCSD(T) barriers lying below $10 \mathrm{kcal} \mathrm{mol}^{-1}$ and becoming smaller for the heavier group IVA atoms. Moreover, all reactions considered are exothermic, with reaction energies

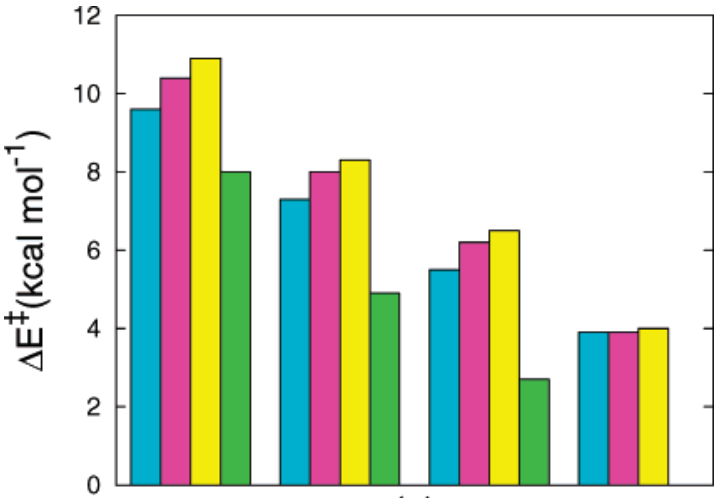

(a)

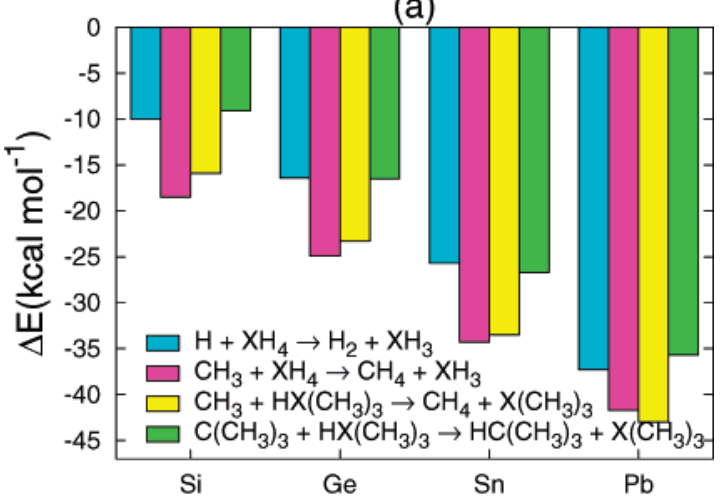

(b)

Figure 5. RMP2/cc-pVDZ[-pp] classical barriers (a) and reaction energies (b) for reactions $1-4$

around -10 to $-45 \mathrm{kcal} \mathrm{mol}^{-1}$, and they become more exothermic for the heavier group IVA atoms. 


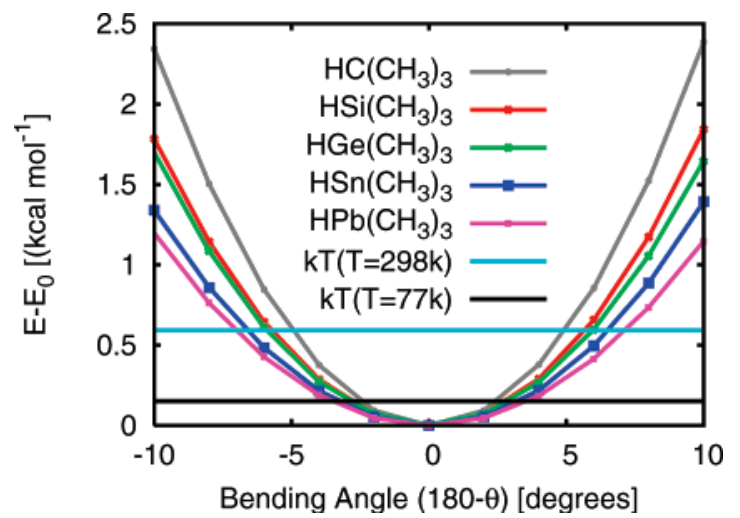

Figure 6. MP2/cc-pVDZ[-PP] $-\mathrm{C}-\mathrm{X}-\mathrm{H}$ bending potential for $\mathrm{HX}\left(\mathrm{CH}_{3}\right)_{3}$, where $\mathrm{X}=\mathrm{C}, \mathrm{Si}, \mathrm{Ge}, \mathrm{Sn}$, and $\mathrm{Pb}$

3.5. Hydrogen Donation Tool. Having considered the general features of these hydrogen transfer reactions, let us consider how the present results impact proposed schemes for the mechanosynthesis of diamond or other hydrocarbons, which require the selective abstraction and donation of hydrogen atoms. For such an approach to be realized, it is imperative that the hydrogen abstraction and donation tools have favorable thermodynamics, facile kinetics, and good positional control. ${ }^{1-6}$ The most natural tool for these purposes would be something like a scanning probe microscope (SPM) ${ }^{2}$ whose tip is modified for the purposes of hydrogen abstraction or donation. Such techniques have already been used for subnanometer manipulation of atoms. ${ }^{10}$ For hydrogen donation, we can model the SPM tip with a $\mathrm{Si} / \mathrm{Ge} / \mathrm{Sn} / \mathrm{Pb}$-substituted isobutane. As indicated above, the donation of a hydrogen from such a tool would have low activation barriers and negative reaction energies, particularly when using $\mathrm{Ge}, \mathrm{Sn}$, or $\mathrm{Pb}$ atoms.

Figure 5 shows general trends in the thermochemistry of the different models we have considered. The MP2/DZ[-PP] classical barriers for our four model reactions decrease monotonically as the group IVA atom changes in the order $\mathrm{Si} \rightarrow \mathrm{Ge} \rightarrow$ $\mathrm{Sn} \rightarrow \mathrm{Pb}$. For each group IVA atom, as the size of our model reactions increases in reactions $1-3$, we notice a moderate increase in classical barriers. However, there is a significant drop in the MP2/DZ[-PP] classical barrier heights going from reaction 3 to 4 , our largest model. On the contrary, B3LYP/ $\mathrm{DZ}[-\mathrm{PP}]$ and BHLYP/DZ[-PP] predict a significant increase in the classical barrier upon going from reaction 3 to 4 . Since reactions 3 and 4 are too large for a $\operatorname{CCSD}(\mathrm{T})$ transition state search, we approximated the CCSD(T) barriers by performing $\operatorname{CCSD}(\mathrm{T})$ single-point energy computations at the MP2 and BHLYP optimized geometries, which we might refer to as CCSD(T)//MP2 and CCSD(T)//BHLYP, respectively. Although the MP2 and BHLYP optimized geometries are quite different, both the CCSD(T)//MP2 and CCSD(T)//BHLYP barriers exhibit a dip in the reaction energy in proceeding from reaction 3 to 4 , indicating that the behavior in the MP2 classical barriers is not an artifact. One of the implications of these findings for reaction 4 is that, contrary to the picture painted by reactions $1-3$, the classical barrier to hydrogen donation does not monotonically

TABLE 6: Energies of Activation $\left(\Delta E^{\ddagger}\right)$ and Reaction $\left(\Delta E, \mathrm{kcal} \mathrm{mol}^{-1}\right)$ for Tin-Based Reactions ${ }^{a, b}$

\begin{tabular}{|c|c|c|c|c|c|c|c|c|c|c|c|c|c|}
\hline & \multicolumn{3}{|c|}{ B3LYP } & \multicolumn{3}{|c|}{ BHLYP } & \multicolumn{3}{|c|}{ MP2 } & \multicolumn{3}{|c|}{$\operatorname{CCSD}(\mathrm{T})$} & \multirow[b]{2}{*}{ expt } \\
\hline & DZ-PP & TZ-PP & QZ-PP & DZ-PP & TZ-PP & QZ-PP & DZ-PP & TZ-PP & QZ-PP & DZ-PP & TZ-PP & QZ-PP & \\
\hline $\begin{array}{l}\Delta E^{\ddagger} \\
\Delta H^{\ddagger}(0) \\
\Delta H^{\ddagger}(298) \\
E_{\mathrm{a}}(298) \\
E_{\mathrm{a}}(298)-\mathrm{W}\end{array}$ & $\begin{array}{l}0.0 \\
0.2 \\
0.2 \\
1.4 \\
1.4\end{array}$ & $\begin{array}{l}0.1 \\
0.3 \\
0.3 \\
1.5 \\
1.5\end{array}$ & $\begin{array}{l}0.1 \\
0.3 \\
0.3 \\
1.5 \\
1.5\end{array}$ & $\begin{array}{l}1.2 \\
1.2 \\
1.0 \\
2.2 \\
1.9\end{array}$ & $\begin{array}{l}\cdot \mathrm{H}+ \\
1.3 \\
1.3 \\
1.1 \\
2.3 \\
2.0\end{array}$ & $\begin{array}{r}\mathrm{SnH}_{4} \rightarrow \mathrm{I} \\
1.3 \\
1.3 \\
1.1 \\
2.3 \\
2.0\end{array}$ & $\begin{array}{c}+\cdot \mathrm{SnH} \\
5.5 \\
5.3 \\
5.0 \\
6.2 \\
5.4\end{array}$ & $\begin{array}{l}4.4 \\
4.2 \\
3.9 \\
5.1 \\
4.3\end{array}$ & $\begin{array}{l}4.1 \\
3.9 \\
3.6 \\
4.8 \\
4.0\end{array}$ & $\begin{array}{l}3.6 \\
3.4 \\
3.1 \\
4.3 \\
3.8\end{array}$ & $\begin{array}{l}2.3 \\
2.1 \\
1.8 \\
3.0 \\
2.5\end{array}$ & $\begin{array}{l}2.0 \\
1.8 \\
1.5 \\
2.7 \\
2.2\end{array}$ & \\
\hline $\begin{array}{l}\Delta E \\
\Delta H(0) \\
\Delta H(298)\end{array}$ & $\begin{array}{l}-29.5 \\
-28.5 \\
-28.0\end{array}$ & $\begin{array}{l}-31.8 \\
-30.8 \\
-30.3\end{array}$ & $\begin{array}{l}-31.5 \\
-30.5 \\
-30.0\end{array}$ & $\begin{array}{l}-27.6 \\
-26.5 \\
-26.0\end{array}$ & $\begin{array}{l}-29.7 \\
-28.6 \\
-28.1\end{array}$ & $\begin{array}{l}-29.5 \\
-28.4 \\
-27.9\end{array}$ & $\begin{array}{l}-25.7 \\
-24.6 \\
-24.1\end{array}$ & $\begin{array}{l}-28.0 \\
-26.9 \\
-26.4\end{array}$ & $\begin{array}{l}-27.9 \\
-26.8 \\
-26.3\end{array}$ & $\begin{array}{l}-28.0 \\
-26.9 \\
-26.4\end{array}$ & $\begin{array}{l}-29.9 \\
-28.8 \\
-28.3\end{array}$ & $\begin{array}{l}-29.8 \\
-29.7 \\
-28.2\end{array}$ & \\
\hline $\begin{array}{l}\Delta E^{\ddagger} \\
\Delta H^{\ddagger}(0) \\
\Delta H^{\ddagger}(298) \\
E_{\mathrm{a}}(298) \\
E_{\mathrm{a}}(298)-\mathrm{W}\end{array}$ & $\begin{array}{l}1.7 \\
2.7 \\
2.0 \\
3.2 \\
3.1\end{array}$ & $\begin{array}{l}2.2 \\
3.2 \\
2.5 \\
3.7 \\
3.6\end{array}$ & $\begin{array}{l}2.4 \\
3.4 \\
2.7 \\
3.9 \\
3.8\end{array}$ & $\begin{array}{l}5.0 \\
5.8 \\
5.0 \\
6.2 \\
5.8\end{array}$ & $\begin{array}{r}\cdot \mathrm{CH}_{3}+ \\
5.5 \\
6.3 \\
5.5 \\
6.7 \\
6.3\end{array}$ & $\begin{array}{r}\mathrm{SnH}_{4} \rightarrow \\
5.6 \\
6.4 \\
5.6 \\
6.8 \\
6.4\end{array}$ & $\begin{array}{r}\mathrm{H}_{4}+\cdot \mathrm{Sn} \\
6.3 \\
6.7 \\
6.0 \\
7.2 \\
6.7\end{array}$ & $\begin{array}{l}5.1 \\
5.5 \\
4.8 \\
6.0 \\
5.5\end{array}$ & $\begin{array}{l}4.8 \\
5.2 \\
4.5 \\
5.7 \\
5.2\end{array}$ & $\begin{array}{l}5.9 \\
6.4 \\
5.7 \\
6.8 \\
6.4\end{array}$ & $\begin{array}{l}4.4 \\
4.9 \\
4.2 \\
5.3 \\
4.9\end{array}$ & $\begin{array}{l}4.2 \\
4.7 \\
4.0 \\
5.1 \\
4.7\end{array}$ & \\
\hline $\begin{array}{l}\Delta E \\
\Delta H(0) \\
\Delta H(298)\end{array}$ & $\begin{array}{l}-30.4 \\
-26.3 \\
-26.5\end{array}$ & $\begin{array}{l}-33.7 \\
-29.6 \\
-29.8\end{array}$ & $\begin{array}{l}-33.2 \\
-29.1 \\
-29.3\end{array}$ & $\begin{array}{l}-31.6 \\
-27.2 \\
-27.5\end{array}$ & $\begin{array}{l}-31.9 \\
-27.5 \\
-27.8\end{array}$ & $\begin{array}{l}-31.4 \\
-27.0 \\
-27.3\end{array}$ & $\begin{array}{l}-34.3 \\
-30.0 \\
-30.2\end{array}$ & $\begin{array}{l}-34.7 \\
-30.4 \\
-30.6\end{array}$ & $\begin{array}{l}-34.4 \\
-30.1 \\
-30.3\end{array}$ & $\begin{array}{l}-32.4 \\
-28.0 \\
-28.3\end{array}$ & $\begin{array}{l}-32.9 \\
-28.5 \\
-28.8\end{array}$ & $\begin{array}{l}-32.7 \\
-28.3 \\
-28.6\end{array}$ & \\
\hline $\begin{array}{l}\Delta E^{\ddagger} \\
\Delta H^{\ddagger}(0) \\
\Delta H^{\ddagger}(298) \\
E_{\mathrm{a}}(298) \\
E_{\mathrm{a}}(298)-\mathrm{W}\end{array}$ & $\begin{array}{l}2.4 \\
3.1 \\
2.7 \\
3.8 \\
3.8\end{array}$ & & & $\begin{array}{l}\cdot \\
6.0 \\
6.4 \\
6.0 \\
7.2 \\
6.7\end{array}$ & $\mathrm{H}_{3}+\mathrm{HS}$ & $\left.\mathrm{CH}_{3}\right)_{3} \rightarrow$ & $\begin{array}{c}\mathrm{CH}_{4}+\cdot \cdot \mathrm{S} \\
6.5 \\
6.4 \\
5.7 \\
6.9 \\
6.3\end{array}$ & $\left.\mathrm{CH}_{3}\right)_{3}$ & & & & & $3.2^{c}$ \\
\hline $\begin{array}{l}\Delta E \\
\Delta H(0) \\
\Delta H(298)\end{array}$ & $\begin{array}{l}-30.9 \\
-26.4 \\
-26.7\end{array}$ & & & $\begin{array}{l}-31.1 \\
-26.3 \\
-26.6\end{array}$ & & & $\begin{array}{l}-33.5 \\
-28.7 \\
-29.1\end{array}$ & & & $\begin{array}{l}-31.5^{d} \\
-26.7^{d} \\
-27.1^{d}\end{array}$ & & & \\
\hline \multicolumn{14}{|c|}{$\cdot \mathrm{C}\left(\mathrm{CH}_{3}\right)_{3}+\mathrm{HSn}\left(\mathrm{CH}_{3}\right)_{3} \rightarrow \mathrm{HC}\left(\mathrm{CH}_{3}\right)_{3}+\cdot \mathrm{Sn}\left(\mathrm{CH}_{3}\right)_{3}$} \\
\hline $\begin{array}{l}\Delta E \\
\Delta H(0) \\
\Delta H(298)\end{array}$ & $\begin{array}{l}-22.3 \\
-17.8 \\
-18.3\end{array}$ & & & $\begin{array}{l}-21.4 \\
-16.8 \\
-17.4\end{array}$ & & & $\begin{array}{l}-26.7 \\
-22.4 \\
-22.9\end{array}$ & & & $\begin{array}{l}-24.2^{d} \\
-19.9^{d} \\
-20.4^{d}\end{array}$ & & & \\
\hline
\end{tabular}

${ }^{a}$ All ZPVE, thermal, and Wigner tunneling corrections evaluated using cc-pVDZ basis unless indicated otherwise. ${ }^{b} \mathrm{DZ}$, TZ, and QZ denote cc-pVDZ, cc-pVTZ, and cc-pVQZ basis sets, respectively. ${ }^{c}$ Ref $27 .{ }^{d}$ Thermal and ZPVE corrections computed using MP2 frequencies. 
TABLE 7: Energies of Activation $\left(\Delta E^{\ddagger}\right)$ and Reaction $\left(\Delta E, \mathrm{kcal} \mathrm{mol}^{-1}\right)$ for Lead-Based Reactions $\mathrm{s}^{a, b}$

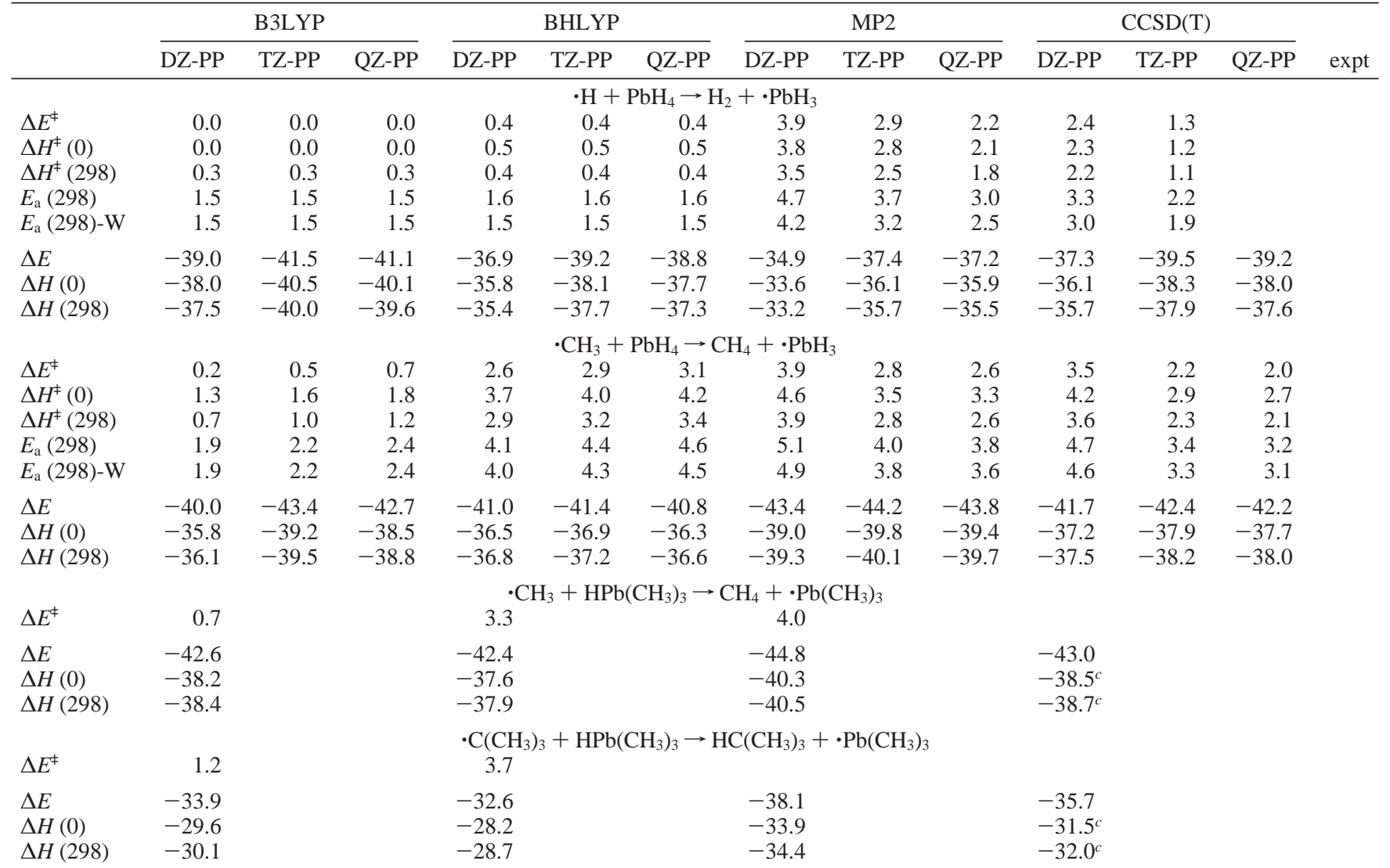

${ }^{a}$ All ZPVE, thermal, and Wigner tunneling corrections evaluated using cc-pVDZ basis unless indicated otherwise. ${ }^{b} \mathrm{DZ}$, TZ, and QZ denote cc-pVDZ, cc-pVTZ, and cc-pVQZ basis sets, respectively. ${ }^{c}$ Thermal and ZPVE corrections computed using MP2 frequencies.

increase with system size. Thus, in an actual experimental hydrogen donation reaction in which a much larger hydrogen donation tool is being used, the barrier to the reaction would likely remain small, according to the results for reaction 4 obtained by MP2, CCSD(T)//MP2, and CCSD(T)//BHLYP computations.

The energies of reaction become progressively more exothermic as the group IVA atom gets heavier. For a given metal/ metalloid, the energies of reaction are somewhat smaller for reactions 1 and 4 than for reactions 2 and 3. The reaction energy for reaction 4 is, at the MP2/cc-pVDZ[-PP] level, $\sim 7 \mathrm{kcal} \mathrm{mol}^{-1}$ less exothermic than that for reaction 3 for each of the group IVA atoms considered. This is in good agreement with the $8 \mathrm{kcal} \mathrm{mol}^{-1}$ change that would be expected on the basis of the $\mathrm{C}-\mathrm{H}$ bond dissociation energies in $\mathrm{H}-\mathrm{CH}_{3}$ vs $\mathrm{H}-\mathrm{C}\left(\mathrm{CH}_{3}\right)_{3}{ }^{60}$

Of the four models of hydrogen transfer reactions studied, the reactions of type $\cdot \mathrm{C}\left(\mathrm{CH}_{3}\right)_{3}+\mathrm{HX}\left(\mathrm{CH}_{3}\right)_{3} \rightarrow \mathrm{HC}\left(\mathrm{CH}_{3}\right)_{3}+$ $\cdot \mathrm{X}\left(\mathrm{CH}_{3}\right)_{3}$ represent the best model of hydrogen donation in a mechanosynthesis scheme, in which the hydrogen donor containing a weak bond between hydrogen and a group IVA atom would be bound via a hydrocarbon linker to an SPM tip. Upon approaching a radical site, the hydrogen bound to the metal/ metalloid would be abstracted by the radical site. Ideally, one would want this abstraction process to be kinetically fast and positionally selective. Of the four group IVA atoms considered, the lead-containing tool has the smallest barrier to hydrogen donation $\left(\Delta E^{\ddagger}=3.7 \mathrm{kcal} \mathrm{mol}^{-1}\right.$ at the BHLYP/cc-pVDZ-PP level). The reaction is also the most exothermic with a $\Delta H(298)$ of $-32.0 \mathrm{kcal} \mathrm{mol}^{-1}$ at the $\operatorname{CCSD}(\mathrm{T}) / \mathrm{cc}-\mathrm{pVDZ}-\mathrm{PP}$ level (with MP2 vibrational corrections). Nevertheless, this model reaction is adequate for the required hydrogen donation function using any of the group IVA atoms considered.
TABLE 8: Positional Uncertainty of $\mathrm{HX}\left(\mathrm{CH}_{3}\right)_{3}$ (where $\mathrm{X}=$ $\mathrm{Si}, \mathrm{Ge}, \mathrm{Sn}, \mathrm{Pb})$ Computed from Classical Turning Points ${ }^{a}$

\begin{tabular}{ccccccc}
\hline & & \multicolumn{2}{c}{$\begin{array}{c}\text { angular } \\
\text { uncertainty }(\mathrm{deg})\end{array}$} & & \multicolumn{2}{c}{$\begin{array}{c}\text { positional } \\
\text { uncertainty }(\AA)\end{array}$} \\
\cline { 3 - 4 } & $R[\mathrm{X}-\mathrm{H}](\AA)$ & $77 \mathrm{~K}$ & $298 \mathrm{~K}$ & & $77 \mathrm{~K}$ & $298 \mathrm{~K}$ \\
\hline $\mathrm{C}$ & 1.11 & 2.4 & 4.9 & & 0.05 & 0.09 \\
$\mathrm{Si}$ & 1.50 & 2.8 & 5.7 & & 0.07 & 0.15 \\
$\mathrm{Ge}$ & 1.55 & 2.8 & 5.9 & & 0.08 & 0.16 \\
$\mathrm{Sn}$ & 1.73 & 3.2 & 6.6 & & 0.10 & 0.20 \\
$\mathrm{~Pb}$ & 1.78 & 3.5 & 7.0 & & 0.11 & 0.22
\end{tabular}

${ }^{a}$ All computations performed at MP2/DZ[-PP] level. ${ }^{b}$ cc-pVDZ basis set for $\mathrm{Si}$ and cc-pVDZ-PP pseudopotential for $\mathrm{Ge}, \mathrm{Sn}$ and $\mathrm{Pb}$.

Figure 6 shows the $\mathrm{C}-\mathrm{X}-\mathrm{H}(\mathrm{X}=\mathrm{Si}, \mathrm{Ge}, \mathrm{Sn}, \mathrm{Pb})$ bending potential of $\mathrm{HX}\left(\mathrm{CH}_{3}\right)_{3}$ computed at the MP2/cc-pVDZ[-PP] level of theory. Since many modes contribute to the $\mathrm{C}-\mathrm{X}-\mathrm{H}$ bending, it was not possible to estimate the positional selectivity by consideration of the energy levels of a single vibrational normal mode. One can, however, take the potential energy curve for displacements along a simple bending coordinate and compute the classical turning points (ignoring zero-point vibrational energy). Using this potential, we can then roughly approximate the positional uncertainty of the hydrogen donor due to thermal motion at a given temperature. Table 8 lists the classical turning points and associated positional uncertainties for tools with the various metals/metalloids. The bending curve is generated by fixing $\mathrm{HX}\left(\mathrm{CH}_{3}\right)_{3}$ at its RMP2/cc-pVDZ[-PP] optimized geometry and varying only the $\mathrm{H}-\mathrm{X}-\mathrm{C}$ bending coordinate. Positional uncertainty is $<0.22 \AA$ at $298 \mathrm{~K}$ for all tooltips, or one-tenth the $\sim 2.5 \AA$ average spacing between two closest hydrogens on the H-terminated $\mathrm{C}(111)$ diamond sur- 
face ${ }^{11}$ potentially allowing excellent positional control during hydrogen donation.

A legitimate concern for the feasibility of hydrogen donation via a lead-based tool is whether the weakly bonded hydrogen is bound tightly enough to be maneuvered around and donated to a radical site. The $\mathrm{X}-\mathrm{H}(\mathrm{X}=\mathrm{Si}, \mathrm{Ge}, \mathrm{Sn}, \mathrm{Pb})$ bond strength in the tooltip can be gauged from the bond enthalpy, $\mathrm{E}_{\mathrm{d}}$, of the analogous $\mathrm{HX}\left(\mathrm{CH}_{3}\right)_{3}$ species. The $\mathrm{X}-\mathrm{H}$ bond enthalpies in the $\mathrm{H}-\mathrm{X}\left(\mathrm{CH}_{3}\right)_{3}$ models increase in the order $\mathrm{Pb}-\mathrm{H}(57.8)<\mathrm{Sn}-\mathrm{H}$ $(69.2)<\mathrm{Ge}-\mathrm{H}(78.8)<\mathrm{Si}-\mathrm{H}(86.0)<\mathrm{C}-\mathrm{H}\left(92.2 \mathrm{kcal} \mathrm{mol}^{-1}\right)$ at the MP2/DZ[-PP] level of theory. The Arrhenius equation for the one-step thermal desorption rate, $k_{1}=\nu \mathrm{e}^{-E_{d} / k_{B} T}$, may be used to crudely approximate the canonical residence time for an $\mathrm{H}$ atom chemisorbed to a tooltip heated to temperature $T .66$ Taking $T=298.15 \mathrm{~K}, E_{\mathrm{d}}=57.8 \mathrm{kcal} \mathrm{mol}^{-1}=2.5 \mathrm{eV}$ for the weakest $\left(\mathrm{CH}_{3}\right)_{3} \mathrm{~Pb}-\mathrm{H}$ tooltip, and the pre-exponential constant $v \sim k_{\mathrm{B}} T / h \sim 6 \times 10^{12} \mathrm{~s}^{-1}$ typically used for thermally migrating chemisorbed hydrogen adatoms on diamond surface ${ }^{66-68}$ (the precise value of which does not sensitively influence the conclusion), the lifetime of the $\mathrm{H}$ atom against spontaneous dissociation from the $\mathrm{Pb}$-based tooltip is $k_{1}^{-1} \sim 10^{29} \mathrm{~s}$, allowing sufficient time to maneuver the hydrogen until it reaches the radical site.

\section{Conclusions}

Hydrogen transfer from $\mathrm{Si}-, \mathrm{Ge}-, \mathrm{Sn}-$, and $\mathrm{Pb}$-substituted methane and isobutane to methyl and $t$-butyl radical sites is investigated theoretically using high-level electronic structure theory methods. The importance of using small-core pseudopotentials in obtaining accurate barriers and reaction energies is demonstrated. All of the reactions considered are exothermic with small barriers. With respect to the thermodynamics and kinetics of the essential hydrogen transfer step, the use of a tooltip hydrogen attached to a group IVA element as a possible hydrogen donation tool in the mechanosynthesis of diamondoids appears feasible, with reaction energy barriers decreasing and reaction exoergicities increasing for $\mathrm{Si} \rightarrow \mathrm{Ge} \rightarrow \mathrm{Sn} \rightarrow \mathrm{Pb}$

Acknowledgment. C.D.S. acknowledges a National Science Foundation Grant (Grant no. 0715268). The Center for Computational Molecular Science and Technology is funded through an NSF CRIF grant from NSF (CHE-0443564) by Georgia Tech. The authors thank Prof. Kirk Peterson (Washington State University) for helpful discussions regarding the cc-pVNZ-PP basis sets. R.A.F. acknowledges research grants from Alcor Foundation, Life Extension Foundation, Kurzweil Foundation, and the Institute for Molecular Manufacturing (IMM).

Supporting Information Available: Classical barriers computed with and without diffuse functions for reactions 1 and 2. This material is available free of charge via the Internet at http:// pubs.acs.org.

\section{References and Notes}

(1) Drexler, K. E. J. Vac. Sci. Technol., B 1991, 9, 1394.

(2) Farrell, H. H.; Levinson, M. Phys. Rev. B: Condens. Matter Mater. Phys. 1985, 31, 3593.

(3) Drexler, K. E. Nanosystems: Molecular Machinery, Manufacturing, and Computation; Wiley: New York, 1992.

(4) Merkle, R. C. Chem. Des. Autom. News 1993, 9, 1.

(5) Merkle, R. C. Nanotechnology 1997, 8, 149. 3,319 .

6) Merkle, R. C.; Freitas, R. A., Jr. J. Nanosci. Nanotechnol. 2003,

(7) Peng, J.; Freitas, R. A., Jr.; Merkle, R. C. J. Comput. Theor. Nanosci. 2004, 1, 62 .
(8) Peng, J.; Freitas, R. A., Jr.; Merkle, R. C.; Von Ehr, J. R.; Skidmore, G. D. J. Comput. Theor. Nanosci. 2006, 3, 28.

(9) Mann, D. J.; Peng, J.; Freitas, R. A., Jr.; Merkle, R. C. J. Comput Theor. Nanosci. 2004, 1, 71 .

(10) (a) Chang, X. Y.; Perry, M.; Peploski, J.; Thompson, D. L.; Raff, L. M. J. Chem. Phys. 1993, 99, 4748. (b) Lyding, J. W.; Hess, K.; Abeln, G. C.; Thompson, D. S.; Moore, J. S.; Hersam, M. C.; Foley, E. T.; Lee, J.; Chen, Z.; Hwang, S. T.; Choi, H.; Avouris, P. H.; Kizilyalli, I. C. Appl. Surf. Sci. 1998, 130, 221. (c) Ho, W.; Lee, H. Science 1999, 286, 1719. (d) Lauhon, L. J.; Ho, W. J. Phys. Chem. 2000, 105, 3987. (e) Hla, S.; Rieder, K. Annu. Rev. Phys. Chem. 2003, 54, 307.

(11) Musgrave, C. B.; Perry, J. K.; Merkle, R. C.; Goddard, W. A., III Nanotechnology 1991, 2, 187.

(12) Sinnott, S. B.; Colton, R. J.; White, C. T.; Brenner, D. W. Surf. Sci. 1994, 316, L1055.

(13) Brenner, D. W.; Sinnott, S. B.; Harrison, J. A.; Shenderova, O. A. Nanotechnology 1996, 7, 161.

(14) Lu, H.-F.; Sun, Y.-C. Surf. Sci. 2001, 494, L787.

(15) Temelso, B.; Sherrill, C. D.; Merkle, R. C.; Freitas, R. A. J. Phys. Chem. A 2006, 110, 11160-11173.

(16) Page, M.; Brenner, D. W. J. Am. Chem. Soc. 1991, 113, 3270.

(17) (a) Foley, E. T.; Kam, A. F.; Lyding, J. W.; Avouris, P. H. Phys. Rev. Lett. 1998, 80, 1336. (b) Hersam, M. C.; Abeln, G. C.; Lyding, J. W. Microelectron. Eng. 1999, 47, 235. (c) Oyabu, N.; Custance, O.; Yi, I.; Sugawaran, Y.; Morita, S. Phys. Rev. Lett. 2003, 90, 176102.

(18) Huang, D.; Yamamoto, Y. Appl. Phys. A: Mater. Sci. Process. 1997, 64, 419.

(19) Thirstrup, C.; Sakurai, M.; Nakayama, T. Surf. Sci. 1998, 411, 203.

(20) McIntyre, B. J.; Salmeron, M.; Somorjai, G. A. Science 1994, 265, 1415 .

(21) Müller, W. T.; Klein, D. L.; Lee, T.; Clarke, J.; McEuen, P. L.; Schultz, P. G. Science 1995, 268, 272.

(22) Shimokawa, S.; Namiki, A.; Gamo, M. N.; Ando, T. J. Chem. Phys. 2000, 113, 6916.

(23) Song, L.; Wu, W.; Dong, K.; Hiberty, P. C.; Shaik, S. J. Phys. Chem. A 2002, 106, 11361

(24) (a) Hiberty, P. C.; Flament, J. P.; Noizet, E. Chem. Phys. Lett. 1992 189, 259. (b) Hiberty, P. C.; Humbel, S.; Byrman, C. P.; Van Lenthe, J. H J. Chem. Phys. 1994, 101, 5969. (c) Hiberty, P. C.; Humbel, S.; Archirel P. J. Phys. Chem. 1994, 98, 11697. (d) Hiberty, P. C. In Modern Electronic Structure Theory and Applications in Organic Chemistry; Davidson, E. R., Ed.; Word Scientific: River Edge, NY, 1997; pp 289-367. (e) Hiberty, P. C.; Shaik, S. In Valence Bond Theory; Cooper, D. L., Ed.; Elsevier: Amsterdam, 2002; pp 187-225.

(25) Drozdova, T. I.; Denisov, E. T. Kinet. Catal. 2002, 43, 10

(26) Chatgilialoglu, C.; Ballestri, M.; Escudié, J.; Pailhous, I. Organometallics 1999, 18, 2395.

(27) Zavitsas, A. A.; ChatgiliaIoglu, C. J. Am. Chem. Soc. 1995, 117, 10645

(28) Sugahara, S.; Hosaka, K.; Matsumura, M. Appl. Surf. Sci. 1998, $130,327$.

(29) Olander, J.; Larsson, K. M. E. Thin Solid Films 2004, 458, 191

(30) Srinivasan, E.; Yang, H.; Parsons, G. N. J. Chem. Phys. 1996, 105, 5467.

(31) Pople, J. A.; Head-Gordon, M.; Fox, D. J.; Raghavachari, K.; Curtiss, L. A. J. Chem. Phys. 1989, 90, 5622.

(32) Curtiss, L. A.; Raghavachari, K.; Trucks, G. W.; Pople, J. A. J. Chem. Phys. 1991, 94, 7221-7230.

(33) Curtiss, L. A.; Raghavachari, K.; Pople, J. A. J. Chem. Phys. 1993, 98, 1293.

(34) Curtiss, L. A.; Raghavachari, K.; Redfern, P. C.; Rassolov, V.; Pople, J. A. J. Chem. Phys. 1998, 109, 7764-7776.

(35) Curtiss, L. A.; Redfern, P. C.; Raghavachari, K.; Rassolov, V.;

Pople, J. A. J. Chem. Phys. 1999, 110, 4703-4709.

(36) Baboul, A. G.; Curtiss, L. A.; Redfern, P. C.; Raghavachari, K. J. Chem. Phys. 1999, 110, 7650-7657.

(37) Dunning, T. H. J. Chem. Phys. 1989, 90, 1007

(38) Kendall, R. A.; Dunning, T. H.; Harrison, R. J. J. Chem. Phys 1992, 96, 6796-6806.

(39) Peterson, K. A. J. Chem. Phys. 2003, 119, 11099.

(40) Peterson, K. A.; Figgen, D.; Gooll, E.; Stoll, H.; Dolg, M. J. Chem Phys. 2003, 119, 11113.

(41) Douglas, M.; Kroll, N. M. Ann. Phys. 1974, 82, 89

(42) Werner, H.-J.; Knowles, P. J.; Lindh, R.; Manby, F. R.; Schütz, M.; Celani, P.; Korona, T.; Rauhut, G.; Amos, R. D.; Bernhardsson, A.; Berning, A.; Cooper, D. L.; Deegan, M. J. O.; Dobbyn, A. J.; Eckert, F.; Hampel, C.; Hetzer, G.; Lloyd, A. W.; McNicholas, S. J.; Meyer, W.; Mura, M. E.; Nicklass, A.; Palmieri, P.; Pitzer, R.; Schumann, U.; Stoll, H.; Stone, A. J.; Tarroni, R.; Thorsteinsson, T. Molpro, version 2006.1, a package of ab initio programs, 2006; see http://www.molpro.net.

(43) Basis sets were obtained from the Extensible Computational Chemistry Environment Basis Set Database, Version 02/02/06, as developed and distributed by the Molecular Science Computing Facility, Environmental 
and Molecular Sciences Laboratory, which is part of the Pacific Northwest Laboratory, P.O. Box 999, Richland, Washington 99352, U.S.A., and funded by the U.S. Department of Energy. The Pacific Northwest Laboratory is a multi-program laboratory operated by Battelle Memorial Institute for the U.S. Department of Energy under contract DE-AC06-76RLO 1830. Contact Karen Schuchardt for further information.

(44) Martin, J. M. L.; Sundermann, A. J. Chem. Phys. 2001, 114, 34083420 .

(45) Raghavachari, K.; Trucks, G. W.; Pople, J. A.; Head-Gordon, M. Chem. Phys. Lett. 1989, 157, 479-483.

(46) Amos, R. D.; Andrews, J. S.; Handy, N. C.; Knowles, P. J. Chem. Phys. Lett. 1991, 185, 256-264.

(47) Knowles, P. J.; Hampel, C.; Werner, H.-J. J. Chem. Phys. 1993, 99, 5219-5227

(48) Watts, J. D.; Gauss, J.; Bartlett, R. J. J. Chem. Phys. 1993, 98 8718-8733.

(49) Stephens, P. J.; Devlin, F. J.; Chabalowski, C. F.; Frisch, M. J. J. Phys. Chem. 1994, 98, 11623-11627.

(50) Lee, C.; Yang, W.; Parr, R. G. Phys. Rev. B: Condens. Matter Mater. Phys. 1988, 37, 785-789.

(51) Becke, A. D. J. Chem. Phys. 1993, 98, 1372-1377.

(52) Becke, A. D. Phys. Rev. A: At., Mol., Opt. Phys. 1988, 38, 30983100 .

(53) Lynch, B. J.; Fast, P.; Harris, M.; Truhlar, D. J. J. Phys. Chem. A 2000, $104,4811$.

(54) Nguyen, H. M. T.; Chandra, A. K.; Carl, S. A.; Nguyen, M. T. J. Mol. Struct. (THEOCHEM) 2005, 732, 219.

(55) Steinfeld, J. I.; Francisco, J. S.; Hase, W. L. Chemical Kinetics and Dynamics; Prentice Hall: New Jersey, 1989.

(56) Wigner, E. Z. Phys. Chem. B 1932, 19, 203

(57) Bell, R. P. The Tunnel Effect in Chemistry; Chapman and Hall: London, 1980

(58) Hammond, G. S. J. Am. Chem. Soc. 1955, 77, 334-338.

(59) Basch, H.; Hoz, S. J. Phys. Chem. A 1997, 101, 4416.

(60) Lide, D. R., Ed. CRC Handbook of Chemistry and Physics, 87th ed.; CRC Press: Boca Raton, FL, 2006.

(61) Lee, T. J.; Rice, J. E.; Scuseria, G. E.; Schaefer, H. F. Theor. Chim. Acta 1989, 75, 81 .
(63) Janssen, C. L.; Nielsen, I. M. B. Chem. Phys. Lett. 1998, 290, 423430

(64) Leininger, M. L.; Nielsen, I. M. B.; Crawford, T. D.; Janssen, C. L. Chem. Phys. Lett. 2000, 328, 431-436.

(65) Lee, T. J. Chem. Phys. Lett. 2003, 372, 362-367.

(66) Schaich, T.; Braun, J.; Toennies, J. P.; Buck, M.; Woll, C. Surf. Sci. 1997, 385, L958.

(67) Su, C.; Song, K. J.; Wang, Y. L.; Lu, H. L.; Chuang, T. J.; Lin, J. C. J. Chem. Phys. 1997, 107, 7543.

(68) Bobrov, K.; Fisgeer, B.; Shechter, H.; Folman, M.; Hoffman, A Diamond Rel. Mater. 1997, 6, 736.

(69) Arthur, N. L.; Miles, L. A. J. Chem. Soc. Faraday Trans. 1997, 93, 4259 .

(70) Matsui, Y.; Yuuki, A.; Morita, N.; Tachibana, K. Jpn. J. Appl. Phys. Part 1 1987, 26, 1575

(71) Goumri, A.; Yuan, W. J.; Ding, L.; Shi, Y.; Marshall, P. Chem. Phys. 1993, 177, 233

(72) Arthur, N. L.; Bell, T. N. Rev. Chem. Intermed. 1978, 2, 37.

(73) Berkley, R. E.; Safarik, I.; Strausz, O. P.; Gunning, H. E. J. Phys Chem. 1973, 77, 1741 .

(74) O’Neal, H. E.; Pavlou, S.; Lubin, T.; Ring, M. A.; Batt, L. J. Phys. Chem. 1971, 75, 3945.

(75) Strausz, O. P.; Jakubowski, E.; Sandhu, H. S.; Gunning, H. E. J. Chem. Phys. 1969, 51, 552

(76) Morris, E. R.; Thynne, J. C. J. J. Phys. Chem. 1969, 73, 3294

(77) Berkley, R.; Safarik, I.; Gunning, H. E.; Strausz, O. P. J. Phys. Chem. 1973, 77, 1734

(78) Kerr, J. A.; Slater, D. H.; Young, J. C. J. Chem. Soc. A 1967, 1 , 134

(79) Arthur, N. L.; Cooper, I. A.; Miles, L. A. Int. J. Chem. Kinet. 1997, 29, 237.

(80) Arthur, N. L.; Cooper, I. A. J. Chem. Soc. Faraday Trans. 1995 $91,3367$.

(81) Nava, D. F.; Payne, W. A.; Marston, G.; Stief, L. J. J. Geophys. Res. 1993, 98, 5531. 